\title{
Hazard Identification and Scenario Selection of Ship Grounding Accidents
}

\author{
Samy Adly Mansour Youssef ${ }^{1,{ }^{*}}$ and Jeom Kee Paik ${ }^{2,3,4}$
}

1 Marine Engineering Technology Department, Arab Academy for Science, Technology and Maritime Transport, Alexandria 1029, Egypt

${ }^{2}$ Department of Naval Architecture and Ocean Engineering, Pusan National University, Busan 46241, Korea

${ }^{3}$ The Korea Ship and Offshore Research Institute (The Lloyd's Register Foundation Research Centre of Excellence), Pusan National University, Busan 46241, Korea

${ }^{4}$ Department of Mechanical Engineering, University College London, London WC1E 7JE, UK

${ }^{*}$ Corresponding author. S.A.M. Youssef. (Email) samyoussef@aast.edu, (Tel) +201275410420

\begin{abstract}
The objectives of the present paper are to identify the hazard of ship grounding; where a ship runs on a rock with a forward speed, and to select a set of credible scenarios with a limited number that can still represent all possible situations of the accidents. For this purpose, the statistics of ship grounding accidents recorded by authorities for the period of 46 years during 1970 to 2016 are collated. An extensive analysis is undertaken to examine the statistical characteristics in association with random variables influencing the consequence of grounding. A total of six parameters, namely ship's forward speed, ship's trim angle, rock tip eccentricity, rock length, rock width and rock height are considered as random variables where the displacement or mass of the grounded ship is fixed. Each of the random variables is then formulated with a probability density function. A sampling technique is applied to the probabilistic selection of the grounding scenarios which are to be used for the consequence analysis within the framework of quantitative risk assessment. Important insights developed from the present study are discussed. Details of the analyses are documented.
\end{abstract}

\section{Keywords}

Ship grounding, statistical analysis, quantitative risk assessment, grounding scenarios, sampling technique

\section{Introduction}

While in service, ships rarely are subjected to accidents which include grounding, collision, contact, fire, explosion, capsizing and hull girder collapse. Such accidents may result in catastrophic consequences associated with casualties, property damage and environmental pollution. Ship grouding studied in the present paper is one of the most frequent accidents in shipping. When large tankers are involved in a grounding event with breaching one or more cargo tanks, the environmental pollution due to an oil spill becomes a great concern. Figure 1 shows the causes of oil spills with greater than 700 tonnes in amount occurred during 1970-2015 (ITOPF, 2016). It is seen from Figure 1 that grounding accidents take up 33\%. AGCS (2014) indicates that ship grounding takes up 50\% of all marine insurance claims in excess of $1 \mathrm{~m}$ Euro during 2009-2013. Moreover, wreck removal costs can be several times larger than that of the hull value 
in some cases, because rescue and salvage operations are complex and costly as environmental concerns are raised. For example, the passenger vessel "Costa Concordia", which ran aground in 2012, significantly raised many issues to be resolved in the international marine salvage industry and caused new regulations to be set for improving safety performance in wreck removal operations (Senauth, 2013).

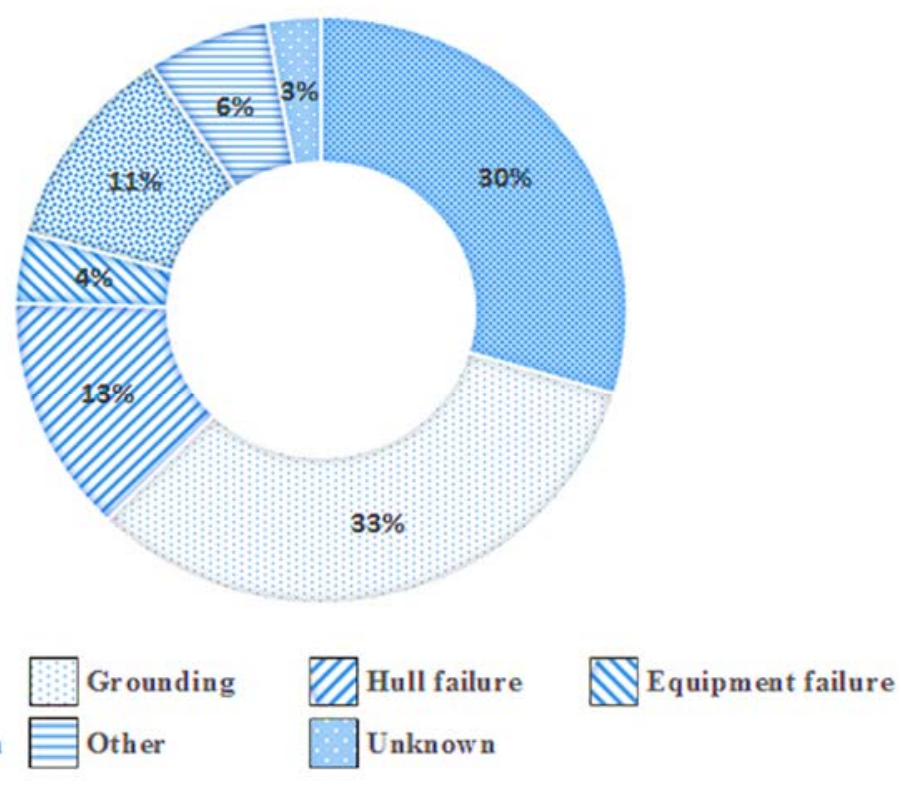

Figure 1. Causes of oil spills with greater than 700 tonnes in amount for the period 1970-2015 (ITOPF, 2016).

The International Maritime Organization (IMO, 2002) introduced a procedure for formal safety assessment (FSA) which is handy in identifying and evaluating risks to personnel, assets and the environment. The FSA procedure comprises five main steps as follows:

- Step 1: Hazard identification.

- Step 2: Risk analysis

- Step 3: Risk control options

- $\quad$ Step 4: Cost-benefit assessment

- Step 5: Decision making and recommendations

In step 1, all potential hazards leading to damages to personnel, asset and the environment are identified. The main result of this step is a list of hazards and associated scenarios which should be prioritized by identified risk level that should be the focus of a more thorough analysis in subsequent phases of the FSA. The accidental scenario identification and selection is the most vital stage of any risk assessment procedure or quantitative risk assessment and management (QRA\&M), which affects all the following stages in the FSA framework.

Two available approaches can be used for the scenario identification stage; deterministic and probabilistic. In the deterministic procedure, a few scenarios are chosen by assuming a certain value for each scenario 
parameter where the ship might be tested under one or more unfavorable accidental scenarios with a relatively low level of occurrence probability, leading to unfavorable consequences. On the other hand, the probabilistic approach identifies the hazards probabilistically with a set of scenarios in association with the random variables affecting the consequences of the accident (Paik and Thayamballi, 2007; Samuelides et al., 2009; Youssef et al., 2016). As ship grounding is rather uncertain and probabilistic in nature, probabilistic approaches are more desirable.

Numerous studies in the literature have used the deterministic approach to choose grounding scenarios, which were implemented in model tests and numerical simulations (Glykas and Das, 2001; Haris and Amdahl, 2012; Hong and Amdahl, 2008, 2012; Liu et al., 2015; Paik and Seo, 2007; Yu et al., 2013; Zeng et al., 2016; Zhang and Suzuki, 2006). In contrast, a few studies have used the probabilistic approach, in which each of grounding parameters has been dealt as a random variable by formulating a distribution function. Based on statistical data collected, Brown and Amrozowicz (1996) introduced a method to define probability density distributions for grounding damage extent as a function of a simplified set of independent variables circumscribing the ship structural design. This method is initially started by formulating probability density functions (pdf's) for ship speed, depth of water and obstruction characteristics. Similar work was conducted by Lützen and Simonsen (2003) where the grounding scenarios were described by pdfs for ship draught, speed and obstruction height, and width. Moreover, such analyses have also been performed by Rawson et al. (1998) and Tikka and Chen (2001). In recent years, the studies on the structural crashworthiness and also the response of post-grounding accidents are also found in the literature (Paik, 2007a, 2007b; Hong and Amdahl, 2008; Khan and Das, 2008; Zipfel and Lehmann, 2012; Samuelides, 2015; Deeb et al., 2017).

In the light of the above discussion, this paper aims the way to select grounding scenarios using the probabilistic approaches. This method commences with collecting grounding accident database from different sources worldwide, followed by a statistical analysis which aids formulating the pdf's for the corresponding parameter of grounding. The derived probability functions are then used to select a set of grounding scenarios that can typify all possible situations. Similar approaches were applied to ship collisions (Youssef et al., 2014a; Youssef et al., 2014b).

\section{Framework of the Applied Methodology}

To choose accidental scenarios, influential parameters governing the accident are defined in Section 3. This can be done by discerning the event first through investigating a large number of historical relevant accidents. The probabilistic method presented in this study starts with gathering information about historical ship grounding accidents to erect a database with a satisfying quality and quantity. The outline of the framework developed in this study is illustrated in Figure 2. The established database will be then employed to perform an extensive statistical analysis. The database and the obtained statistical analysis will carefully be investigated to identify the most effective parameters that control the grounding event. This can also be used to examine the relationships between parameters of influence. 
The historical data distribution for each parameter should be fitted well by a probability density function (pdf) with a description of the range and variability of such parameter. Goodness-of-Fit test (GoF) can be implemented to measure the compatibility of historical data with the candidate pdf's. Due to the significant effect of the histogram bin width (or interval) on the data distribution properties such as the mean, the variance and the coefficient of variance (COV), Paik and Kim (2012) put forward the so-called 'Minimum COV criterion' which guarantees that the degree of variation between the candidate pdf's and the original data distribution will be the lowest. Thus, the bin width that accompanies the largest mean value and the smallest COV shall be selected. By applying the above steps, which are grouped in a dashed box shown in Figure 2, one pdf should be nominated for each grounding parameter identified in advance. Finally, the determined pdf's will be employed as inputs to one of the most confident sampling techniques to contrive a limited number of grounding scenarios, since considering all possible scenarios is not practical. Latin hypercube sampling (LHS) (Ye, 1998) and Monte Carlo simulations (MCS) (Rubinstein, 1982) are the most commonly used sampling techniques. The resulted scenarios can be employed to simulate structural crashworthiness of the grounded ship.

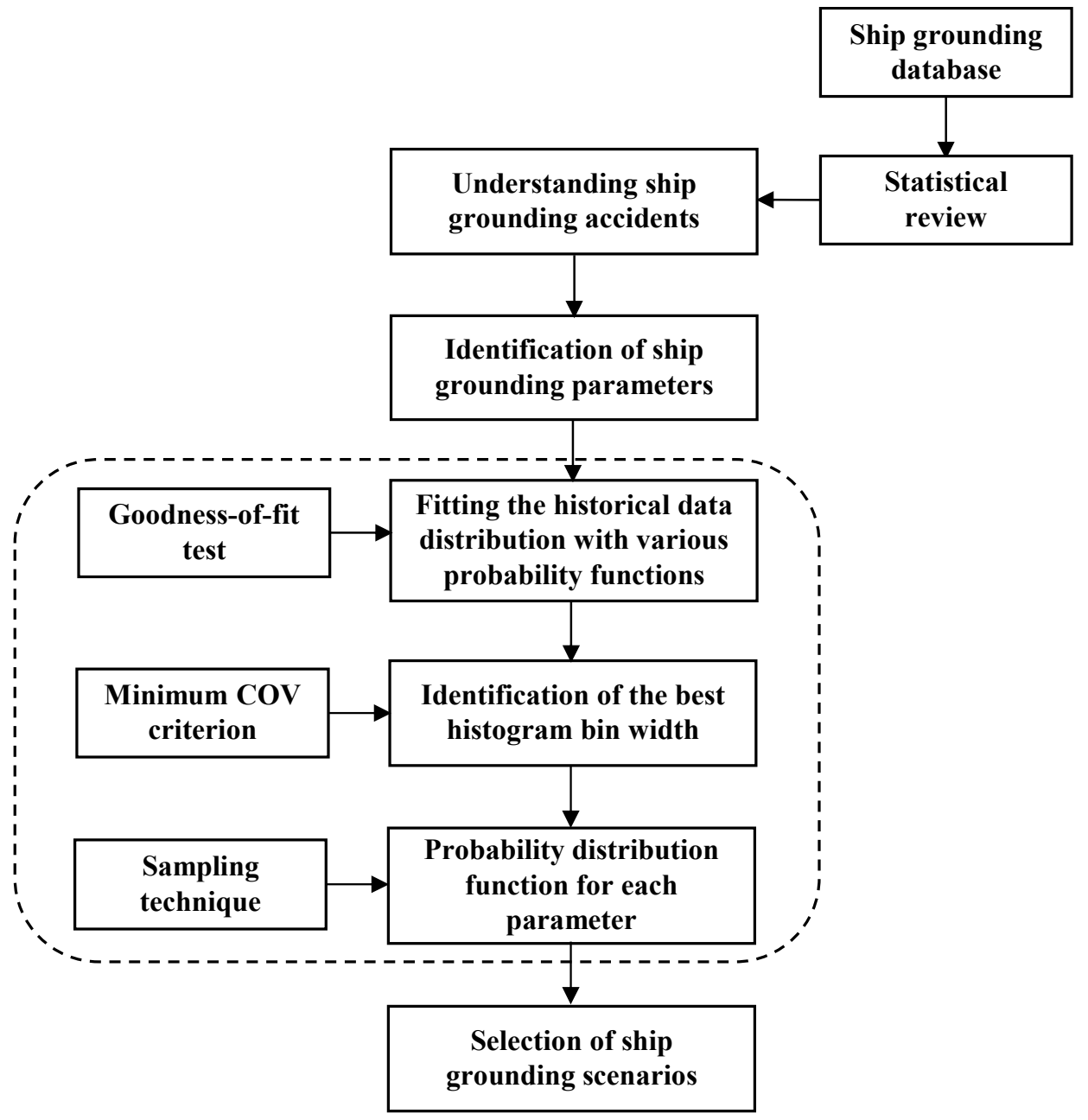


Figure 2 Framework of selecting the grounding scenarios.

\section{Parameters Affecting Ship Grounding Mechanics}

Ship grounding is defined as an accidental event where ship bottom structures are damaged. Typically, ship grounding accidents can be classified into two groups: one is an event where a ship runs on a rock pinnacle with a forward speed, and another group is a stranding situation which is similar to a collision where the bottom structures are subjected to mainly out-of-plane loads (Paik and Thayamballi, 2003). In the first group, the grounding process is distinguished by an obstruction deflects the bottom inward and/or enters into and cuts through the bottom structures as the ship travels forward.

This paper focuses on the former group of grounding, which is usually the consequence of navigational errors associated with failures in the process of passage planning and piloting as well as nautical charts with un-updated data (Fowler and Sørgård, 2000). The grounding damages in this case are governed by the loading in the ship's length direction causing a raking situation as shown in Figure 3. The amount of grounding damages is contingent on the resistance of bottom structures to the penetration as well as operational conditions such as grounding speed, hydrodynamic stability and rock characteristics. This kind of a raking accident often causes a very long gash in the bottom structures. On the other hand, the stranding situation happens when a ship is swept away by waves and tides as the engine power fails, where bottom structures on a rock near shore are damaged by vertical loading due to the difference between buoyancy and weight in ebb tide.

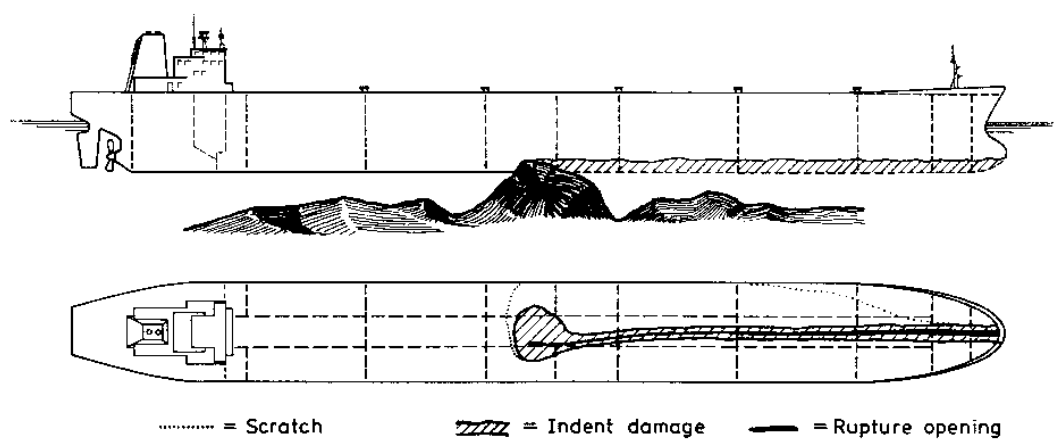

Figure 3. A schematic of the grounding accident and the resulting bottom raking damage distribution (Kuroiwa, 1996; Pedersen and Zhang, 2000a).

Based on the seabed topology (Kaneko, 2012), the grounding can be classified into hard and soft grounding. When the ship runs aground on rocks or hits a rocky side of the coasts by wind or waves, the event can be referred to as 'hard grounding' causing extensive crushing and tearing damage. Contrastingly, the soft grounding refers to the event where a ship runs aground on soft seabed like sandy beaches causing minor damage on a large area in some cases (Lützen and Simonsen, 2003; Mazaheri, 2009). 
Tasks for analyzing ship grounding accidents can be bisected into the following: namely the external mechanics and the internal mechanics (Paik and Thayamballi, 2003). The aim of the external mechanics is to identify the accidental actions or loads, by taking into account the effects of accidental and operational conditions of the grounded ship. The aim of the internal mechanics is to identify the structural consequences of the grounded ship.

Similar to other types of accidents in association with volatility, uncertainty, complexity and ambiguity (VUCA), ship grounding mechanics is also governed by various parameters which are random. Within the framework of quantitative grounding risk assessment and management, it is required to select accidental scenarios associated with the VUCA aspects, which are necessitated to characterize the accidental actions and action effects.

Parameters affecting ship grounding mechanics with the focus on the grounding on a rock with a forward speed can be inventoried as follows:

- mass of the grounded ship,

- $\quad$ ship's forward speed,

- $\quad$ ship's trim angle,

- $\quad$ eccentricity of rock tip,

- length of rock,

- width of rock, and

- height of rock.

In the present study, the parameters noted above are tackled as random variables, except the mass of the grounded ship because the quantatitative grounding risk assessment will be executed for a certain ship in question. Probability density distributions of the parameters are distinguished based on the statistical database of ship grounding accidents. A set of credible grounding scenarios is then selected in a probabilistic way.

\section{Collation of Ship Grounding Accident Database}

Two kinds of casualty databases are available: accessible by the public and privately owned databases (i.e., commercial data). One of the publicly accessible data is the national accident investigation boards (flag administrations). In this study, a ship grounding database has been amassed from more than 600 accidents investigation reports located in the web pages of about 19 national accident investigation boards, transport safety bureaus of different countries and non-governmental associations for the period of 1970-2016 (AIBN, 2017; ATSB, 2017; BEAmer, 2017; BMA, 2017; BSU, 2017; DMIB, 2017; EMSA, 2017; HBMCI, 2017; JTSB, 2017; MAIB, 2017; MARDEP, 2017; MaritimeNZ, 2017; MARS, 2017; MCIB, 2017; MSA, 2017; NTSB, 2017; SHK, 2017; SIA, 2017; TSB, 2017). All of these boards are interested in covering all accidents in national waters, and all accidents involving their nationally flagged vessels worldwide. The acquired casualty data has been filtered by omitting insufficient and unconscionable data as well as deleting the doubles. 
After the database filtration process, the total number of ship grounding accidents became 514 incidents. Unfortunately, not all of publicly accessible accidental reports provide full information about the accident, especially the impact speed, forward and aft draughts at time of accident. Moreover, it's rare to find reports describing the resulted damage in terms of size and location. Table 1 summarizes the quantity of the most governing parameters recorded in the grounding database.

Table 1 Quantity of grounding parameters recorded in the database.

\begin{tabular}{lc}
\hline Parameters & Quantity \\
\hline Complete principal dimension & 458 \\
Deadweight (DWT) & 405 \\
Gross tonnage (GRT) & 481 \\
Age & 458 \\
Impact speed $\left(v_{i}\right)$ & 320 \\
Forward and aft drafts & 198 \\
\hline
\end{tabular}

\subsection{Qualitative investigation of grounding statistics}

Creating accidental scenarios based on historical data needs accurate and comprehensive statistical reviewing. In that aspect, the collected database is used to show some interesting statistics concerning the ship groundings according to the purpose of the study. This is performed by analyzing the number of grounding accidents distribution related to the characteristics of grounded vessels such as; type, size, age, date of accident, speed and the kinetic energy at the time of accident.

The database collected by Simonsen and Hansen (2000) with 200 grounding accidents during the period of 1945-1960 may also be referred to. In the European Union research project titled "HARDER", damage database has been collected including 930 grounding accidents for the period of 1944-2000. HARDER (19992003) has introduced probability density distributions for the damage extents: damage height, width, length, and position. Recently, a similar project called "Goal-Based Damage Stability" (GOALDS) has been launched aiming to improve the current survivability methods of vessels subjected to collision and grounding damage (GOALDS, 2009-2012). In this project, the database developed in the HARDER project has been redefined and enhanced by collecting additional collision and grounding accident data to cover the period of 2000-2009 from additional sources. More details about the GOALDS's updated damage statistics can be found in IMO (2012).

In order to relate the grounding accidents to the ship type, all ships in database have been classified into 10 major categories as follow;

- Tankers: including crude, product and chemical tankers and other liquid carriers.

- Bulk carriers: including dry bulkers and coal carriers.

- Cargo vessels: including general cargo and refrigerated vessels.

- Container vessels. 
- Gas carriers: including liquefied natural gas (LNG) and liquefied petroleum gas (LPG) carriers.

- Roll-on/roll-off (Ro-Ro) vessels: including car carriers, Ro-Ro/cargo, and Ro-Ro container vessels.

- Passengers: including passenger vessels and ferries.

- Mobile offshore drilling units (MODU): including jack-ups, semi-submersibles, and drill ships.

- Fishing vessels: including all types of fishing vessels.

- Other: including, factory vessels, heavy lift vessels, tug boats, pleasure boats and yachts.

Figure 4 shows the distribution of ship types involved in grounding accidents. It is seen that cargo vessels are the most frequently involved in grounding with $31 \%$ of total accidents in the database. This is due to the fact that the shipping routes of the general cargo ships is usually the busiest, and most of them operate in short sea routes or in trafficked coastal areas with enough risk of being damaged by submerged reefs and rocks (Bužančić Primorac and Parunov, 2016).

The ship type's distribution is calculated by inspecting worldwide fleets recorded in the Shipping Intelligence Network of Clarkson's database (Clarkson, 2017). The obtained distribution is then compared with the distributions of ship types in grounding accidents within the database as shown in Figure 5. It is noted that the cargo vessels are overrepresented within the grounding accidents database (IMO, 2012).

Figures 6 and 7 present the number of grounded vessels by one-decade interval and five-years interval, respectively. The figures show that the number of groundings escalates until 2010 with the peak the period of 2005-2010. The number of groundings has dwindled down in recent years with a help of advanced technologies for navigations and designs together with enhanced rules.

Figures 6 and 7 present the number of grounded vessels by a one-decade and a five-years interval, respectively. The figures show that the number of groundings escalates until 2010 with the peak the period of 2005-2010. The same tendency has been observed by Eleftheria et al. (2016) and AGCS (2016) and other studies. This increase in number can attributed to the increased habit of reporting this type of accidents during this period of time (Eleftheria et al., 2016). The number of groundings has witnessed a dwindling down during the following years which happened due to the help of advanced technologies for navigations and designs together with enhanced rules (Bužančić Primorac and Parunov, 2016). 

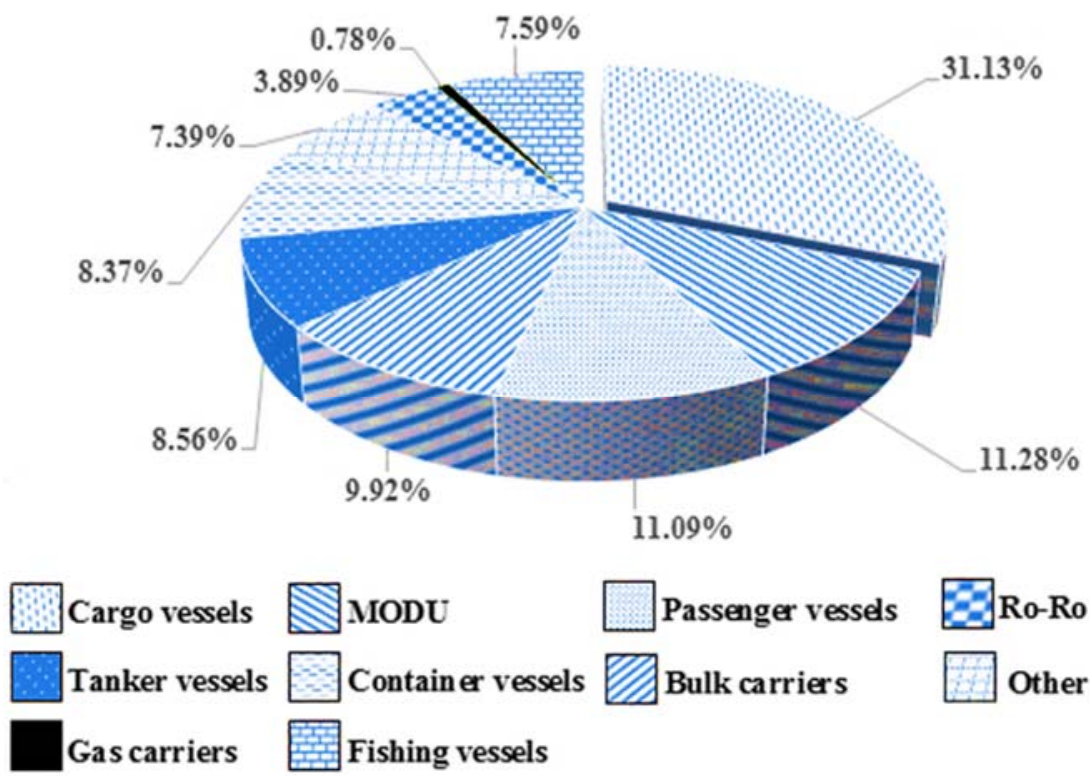

Figure 4. Distribution of ship types in groundings.

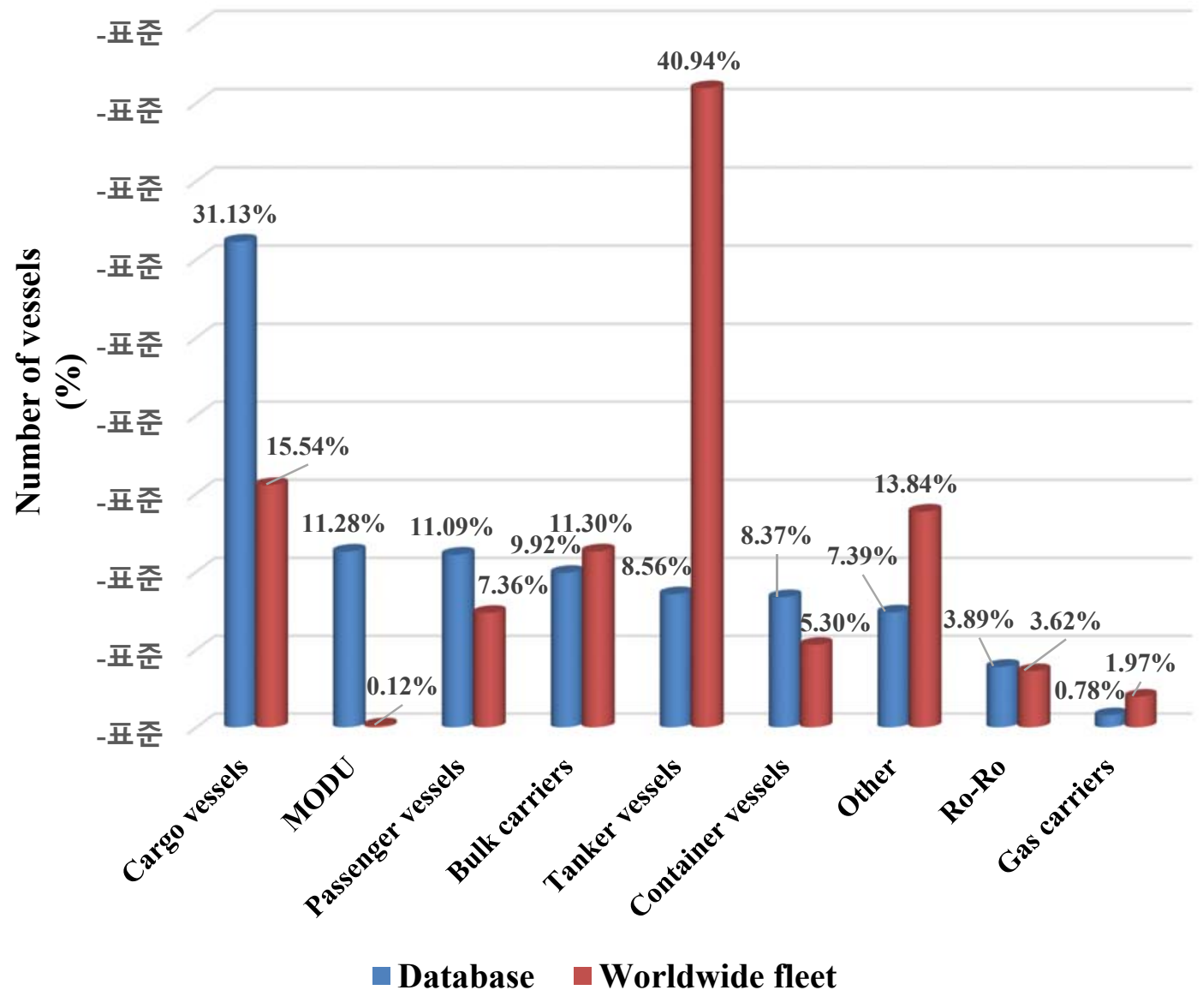


Figure 5 Distribution of ship types in grounding accidents versus the worldwide fleet.

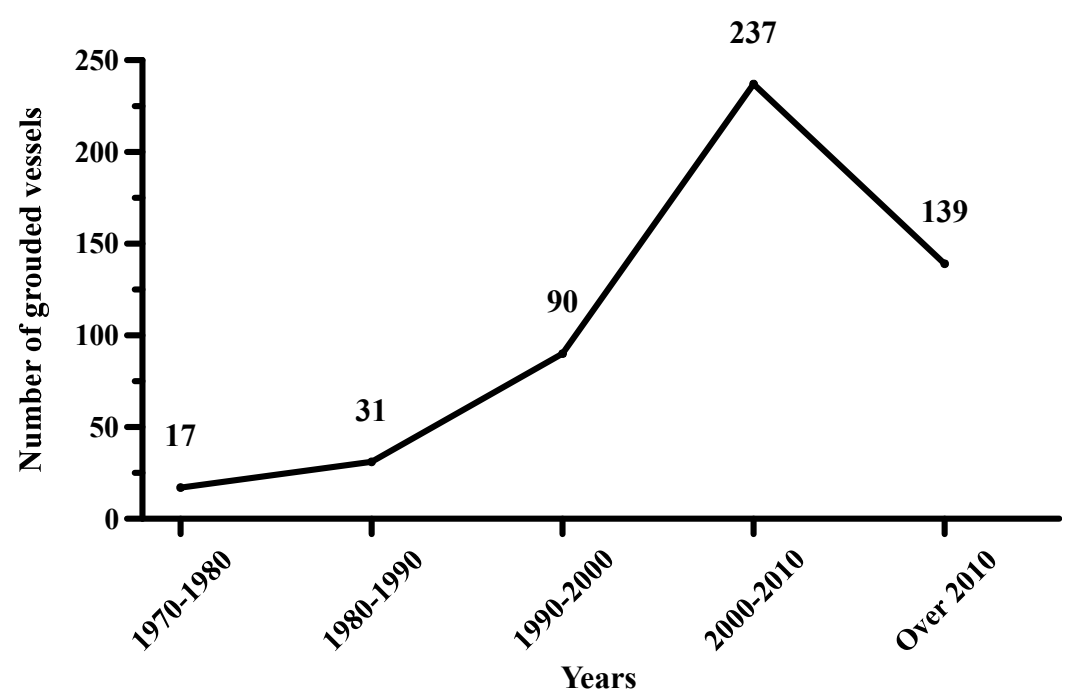

Figure 6 Number of grounded vessels by one-decade interval.

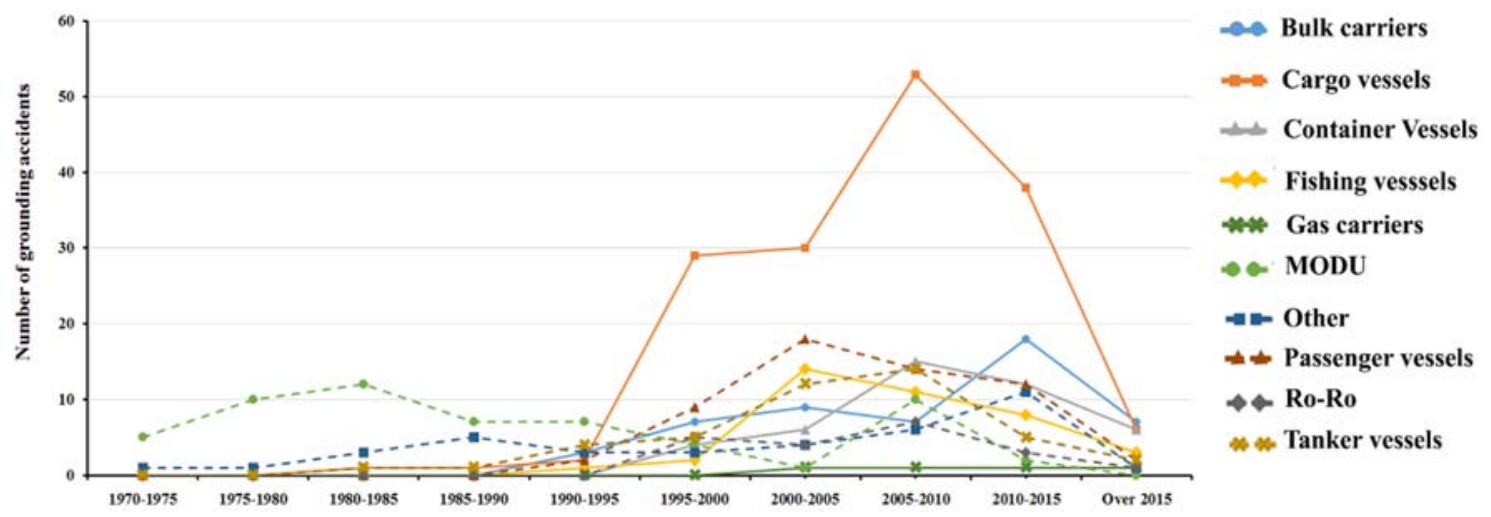

Figure 7 Grounding accidents versus vessel types per five-year interval.

Figure 8 presents the trend of groundings with vessels' age. It is seen that the youngest vessels (below 5 years) are most frequently involved in groundings with $18 \%$ of the accidental database. This may be due to the fact that such young vessels are associated with unprecedented maneuvering incidents, communication problems, crew's inability to handle new technology equipment, their unfamiliarity with the new ship or unexpected failures from the newly installed machinery (Papanikolaou and Eliopoulou, 2008). On the other hand, old vessels (above 25 years) are facing grounding with $24.5 \%$ of the accidental database. This may be due to less advanced navigational equipment onboard and ship performance degradation as well as the reliability of the mechanical parts. Moreover, the improper bridge design in older vessels may cause accidents if the steering, radar and charts are located on different positions of the bridge (Mazaheri, 2009). 


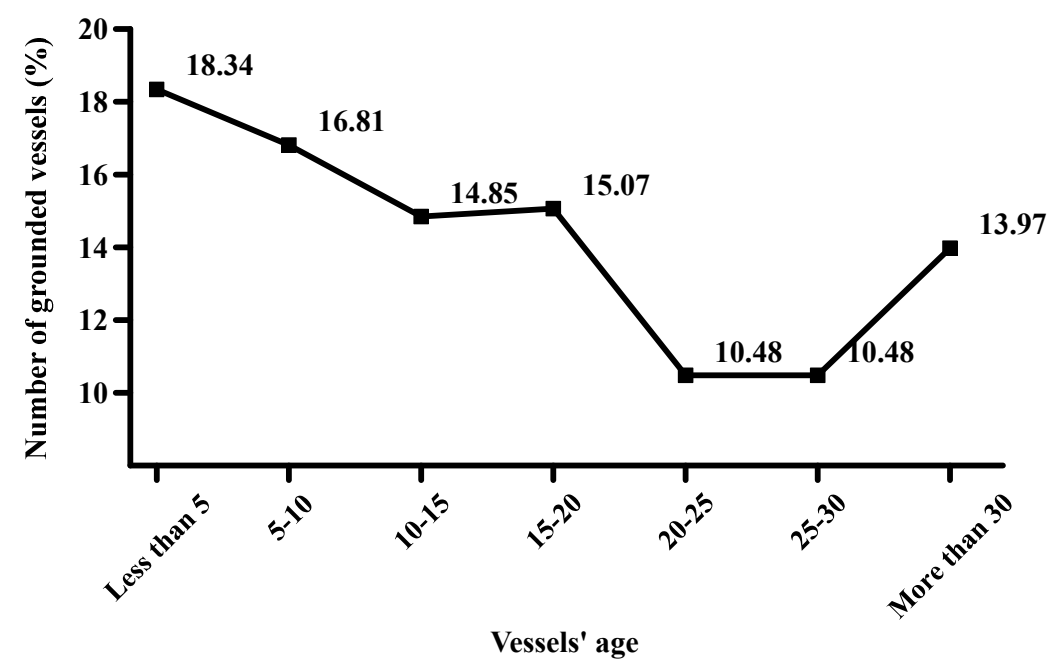

Figure 8 Number of grounded vessels versus ship age.

Focusing on the size of vessels involved in grounding available in the database, the distribution of groundings with respect to ship size in gross tonnage (GT) is explored as shown in figure 9. It is observed that the most groundings occur in vessels below 10,000 GT in size (with 54\% of the total number of vessels in the database) compared to the large-sized vessels greater than 20,000 GT in size. This could reflect the vessel operating routes with frequent visits and sailing near to coastal areas. It is expected because the large majority of which are coaster cargo vessels, tug boats, fishing vessels and pleasure boats. A similar observation was made by Samuelides et al. (2009) and the Norwegian Maritime Directorate (NMD, 2011).

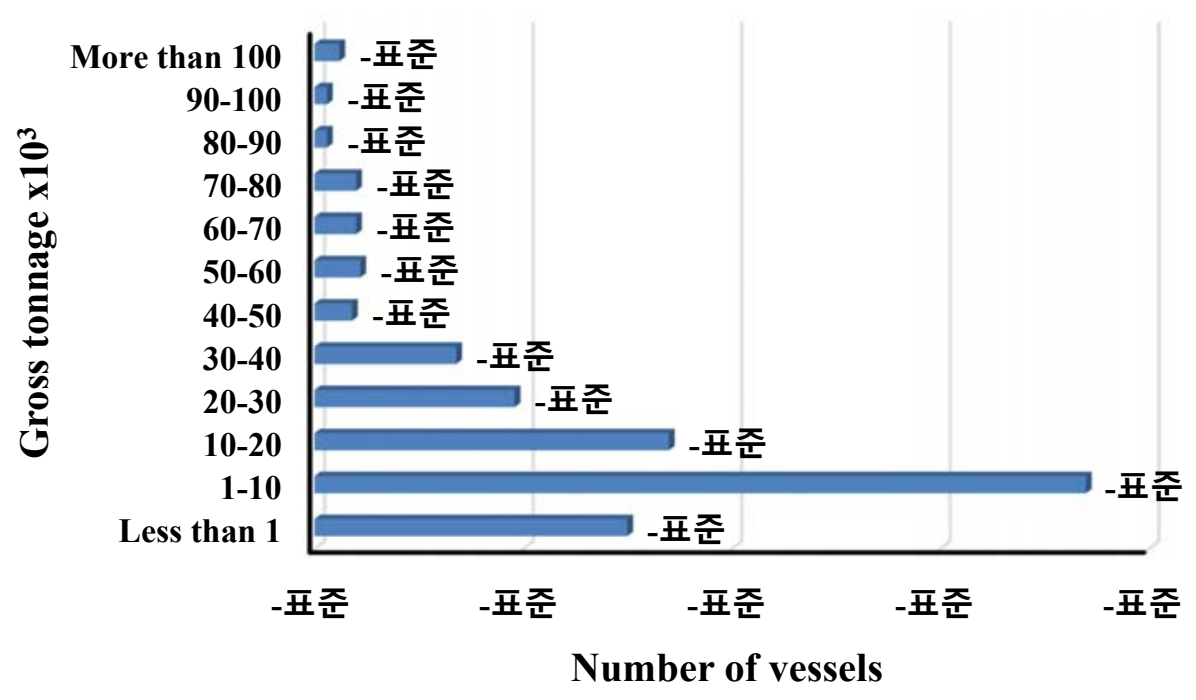

Figure 9 Number of groundings by vessel size in gross tonnage. 
The vessel's speed at time of grounding is one of the most dominating parameters which has a great influence in the estimation of the kinetic energy as well as the resulted structural deformation. Comparing the impact speed $V_{\mathrm{i}}$ with the ship's service speed $V_{\mathrm{s}}$ may reflect the navigator's awareness of the accident. In this regard, the impact speed is defined as the relative ship speed, i.e., $V_{\mathrm{i}} / V_{\mathrm{s}}$ for each grounding case found in the database. Figure 10 shows the distribution of the impact speed in terms of the relative ship speed. It is noticed that the most frequent grounding speed lies between 80 and $100 \%$ of the ship's service speed. A similar observation is also addressed by Cerup-Simonsen et al. (2009).

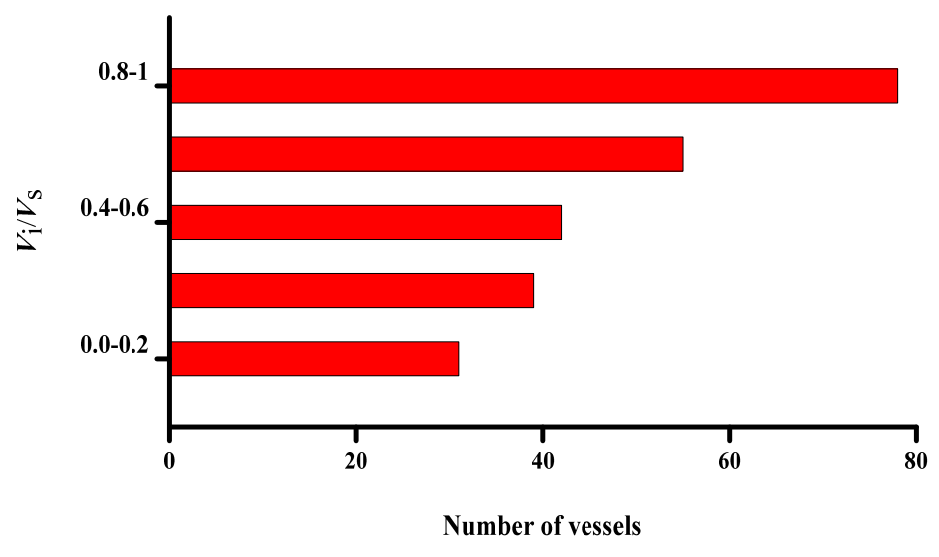

Figure 10 Number of groundings versus non-dimensional impact speed.

The kinetic energy at the moment of grounding can be calculated once the ship displacement and the speed at time of accident are known. The effect of added mass with 5\% of the ship displacement is often considered in industrial practices (Zhu et al., 2002). Figure 11 presents a scatter plot of the $V_{\mathrm{i}} / V_{\mathrm{s}}$ - the corresponding kinetic energy at the time of accident, where no obvious trend is relevant.

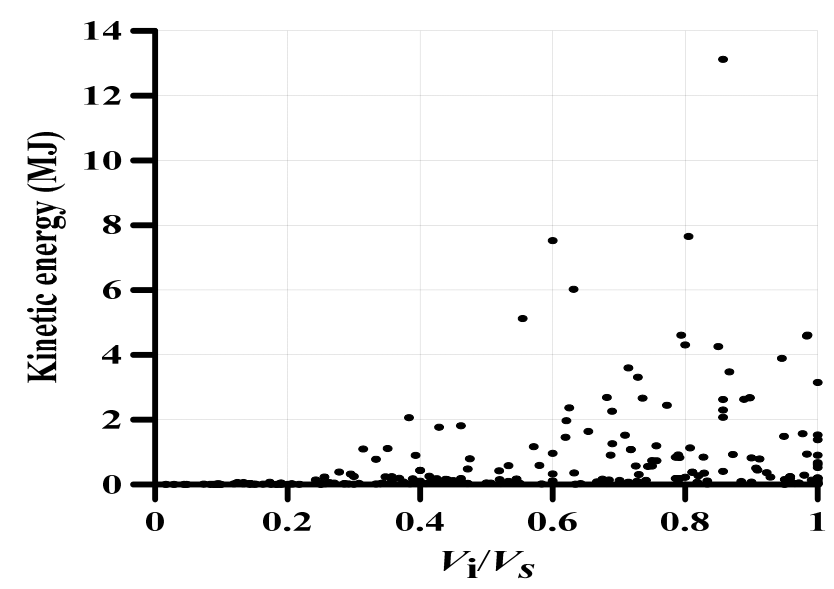

Figure 11 Grounding kinetic energy versus non-dimensional impact speed. 


\subsection{Modelling of seabed obstruction}

The shape and size of the seabed obstruction have an immense effect on the determination of the extent of grounding damage on ships. Alsos and Amdahl (2007) classified the seabed topology into three major types namely rock, shoal and reef. Concerning the resulted bottom damage, rocks cause an extensive plate cutting with deep penetration, while shoals cause a large damage surface with no tearing in some cases. However, there is no adequate information about the seabed topology.

While the seabed is arbitrary in shape, simplified models are available in the literature representing the geometric shape of the seabed: blunted cone-shaped (Naar et al., 2002; Rawson et al., 1998; Simonsen, 1997; Sirkar et al., 1997; Wang et al., 2002), wedge-shaped (Lu and Calladine, 1990; Paik, 1994; Wang et al., 1997), mathematical-modeled rock with polynomial (Heinvee et al., 2013) and paraboloid equations (Nguyen et al., 2011a). The last two types have been used to generate different shapes of the seabed by changing the equation's parameters. Recently, Sormunen et al. (2016) have seen to geological formations of the seabed to develop mathematical rock models for a specific region. Bearing in mind the available historical damage statistics (i.e., extents of damage) from potential sources of sea floor obstruction data, it is possible to establish a simplified indenter by translating such damage data to predict a three-dimensional rock model (Alsos and Amdahl, 2007).

Probabilistic damage models are also available on the basis of large number of collected grounding accidents. IMO (1995) presented a probabilistic procedure for assessing the oil outflow performance of an oil tanker design in collision and grounding based on the damage data of 63 grounding accidents which has been collected during the period of 1980-1990.

In the present study, the seabed topology is associated with the probability density distributions of the damage extents based on GOALDS's updated damage database. By doing this, the longitudinal, transverse, vertical (i.e., penetration) extents of damage can be represented by the length, width, and elevation of the seabed obstruction, respectively (Lützen and Simonsen, 2003). It means that the length and width of the obstruction are measured at the vessel's baseline and the elevation is measured from baseline to the tip of the obstruction (Nguyen et al., 2011b; Pedersen and Zhang, 2000b). A parabolic shape is selected to mathematically represent the seabed obstruction, expressed by Equation (1) that can give an infinite number of shapes. A set of different shapes is generated by heeding the parameters $\mathrm{a}, \mathrm{b}$ and $\mathrm{c}$ as random variables described by pdfs. Figure 11 shows the geometric model of the obstruction shape with its parameters. As shown in Figure 12, the length $(l)$, width $(w)$ and the elevation $(d)$ of the proposed obstruction equal to $2 a, 2 b$, and c, respectively.

$$
-\frac{x^{2}}{a^{2}}+\frac{y^{2}}{b^{2}}=\frac{z}{c}
$$




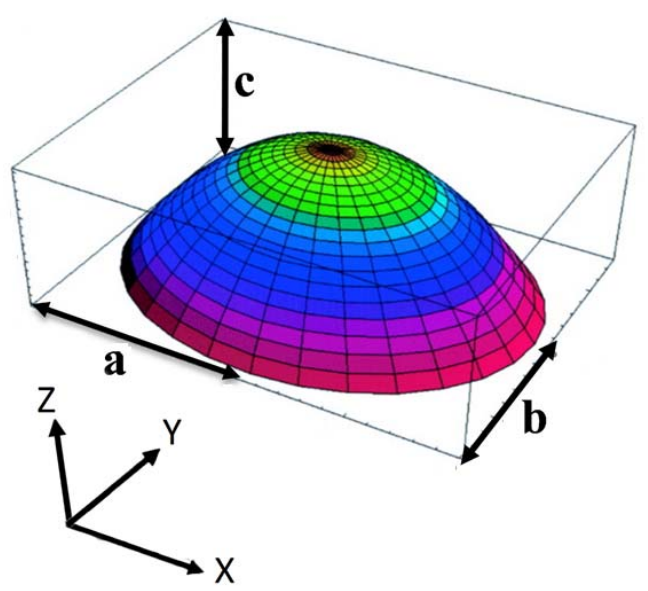

Figure 12 Geometric model of the seabed obstruction shape.

In this model, the obstruction tip eccentricity (i.e., the transversal position of the obstruction along the ship breadth) is not yet realized, as no grounding damage database is available. However, to cover all possible scenarios, it is reasonable to suggest that the obstruction tip position at the ship breadth has a uniform distribution (Bulian et al., 2016; IMO, 1995, 2012; Lützen and Simonsen, 2003).

On the basis of the statistical review done for the database and the available seabed obstruction models, the grounding scenarios herein are characterized by the following parameters;

- Non-dimensional impact speed $\left(V_{\mathrm{i}} / V_{\mathrm{s}}\right)$ : impact speed at time of accident normalised by the ship service speed.

- $\quad$ Ship trim angle $\left(\theta_{t}\right)$ : positive degrees for trim by aft.

- Obstruction tip eccentricity (e): non-dimensional distance from the ship centerline to port or starboard side.

- $\quad$ Obstruction size (see figure 12):

o Non-dimensional obstruction length $(l)$ normalised by the ship length between perpendiculars (L) (l/L) (IMO, 2012).

o Non-dimensional obstruction width $(w)$ normalised by the ship moulded breadth (B) $(w / B)$ (IMO, 2012).

o Non-dimensional obstruction elevation $(d)$ normalised by the ship moulded depth (D) $(d / D)$ (IMO, 2012).

In summary, each scenario can be delineated by six parameters which shall be dealt with as random variables. The limited number of available damage data for passenger ships has concluded to that all damage data, regardless of ship type and time period, shall be considered. The same analyses were undertaken by (HARDER, 1999-2003) and (GOALDS, 2009-2012). 


\section{Probability Density Distributions of Random Variables}

The ship types involved in the collected database are regrouped into six categories, each encompasses several more specific types, as follows:

- All types: including all types of vessels in the database.

- Tankers: including crude, product and chemical tankers as well as gas carriers.

- Bulk carriers: including dry bulkers and coal carriers.

- Cargo vessels: including general cargo and refrigerated vessels.

- Container vessels.

- Passengers: including passenger vessels, ferries and Roll-on/roll-off (Ro-Ro) vessels.

\subsection{All types of Ships}

The range and the variability of each parameter are investigated and illustrated in histograms that represent the historical data. The Goodness-of-Fit $(\mathrm{GoF})$ tests are applied to formulate the probability density distribution using the Kolmogorov-Smirnov test (K-S) (Chakravarty et al., 1967). The K-S test assesses the statistic value which is the largest absolute value of the difference between the historical data and the candidate pdfs. Although there are many theoretical pdfs to fit the historical data, it is not practical to consider them all. Thus, only seven of the most commonly used pdfs are picked to designate the best to fit the historical data. The better the distribution fits the historical data, the smaller the statistic value. Table 2 shows the test statistic value for the candidate pdfs for each parameter in the 'All types of vessels' category. As discussed in the earlier section, a uniform pdf is suggested to represent the data distribution of obstruction tip eccentricity (e) as a non-dimensional distance from the ship centerline to port or starboard side (-B/2, B/2).

Table 2 K-S test statistic values for candidate pdfs for the category including all types of ships.

\begin{tabular}{cccccccc}
\hline & \multicolumn{7}{c}{ Used pdfs } \\
\cline { 2 - 8 } & Logistic & Lognormal & Normal & $\begin{array}{c}\text { 2-P } \\
\text { Weibull }\end{array}$ & $\begin{array}{c}\text { 3-P } \\
\text { Weibull }\end{array}$ & $\begin{array}{c}\text { 2-P } \\
\text { Gamma }\end{array}$ & $\begin{array}{c}\text { 3-P } \\
\text { Gamma }\end{array}$ \\
\cline { 2 - 8 } $\boldsymbol{V}_{\mathbf{i}} / \boldsymbol{V}_{\mathbf{s}}$ & 0.12571 & 0.16722 & 0.10312 & 0.15816 & 0.08902 & 0.14667 & 0.11454 \\
$\boldsymbol{\theta}_{\mathbf{t}}$ & 0.16288 & $\mathrm{n} / \mathrm{a}$ & 0.18547 & $\mathrm{n} / \mathrm{a}$ & 0.23212 & 0.23212 & 0.18482 \\
$\boldsymbol{h} / \mathbf{L}$ & 0.37022 & 0.17949 & 0.36403 & 0.39633 & 0.23879 & 0.33225 & 0.27628 \\
$\boldsymbol{w} / \mathbf{B}$ & 0.39123 & 0.24178 & 0.38263 & 0.29567 & 0.2783 & 0.32976 & 0.2783 \\
$\mathbf{d} / \boldsymbol{D}$ & 0.3834 & 0.29936 & 0.37569 & 0.3428 & 0.31215 & 0.28941 & 0.34448 \\
\hline
\end{tabular}

Note: $2-\mathrm{P}=$ two parameters, $3-\mathrm{P}=$ three parameters.

To manage the effect of the histogram bin width (interval) on the distribution parameters, the so-called 'minimum COV criterion' is effectuated for the selected pdf for each parameter. In this step, the mean and COV values are examined for various histograms' bin width. The bin width that corresponds to the largest 
mean and the lowest COV is selected as shown in Figure 13. The selected pdfs for each grounding parameter that best represent the historical data based on the examination results of the K-S test, and the effect of the histogram bin width are shown in Figure 14.

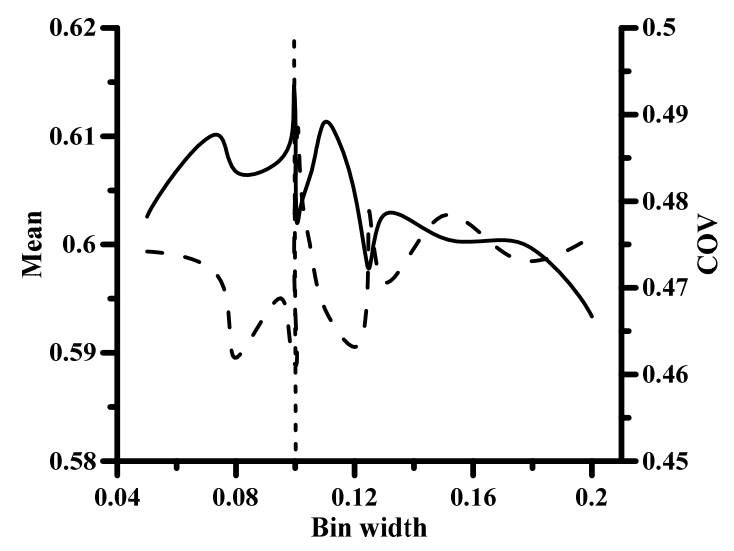

(a)

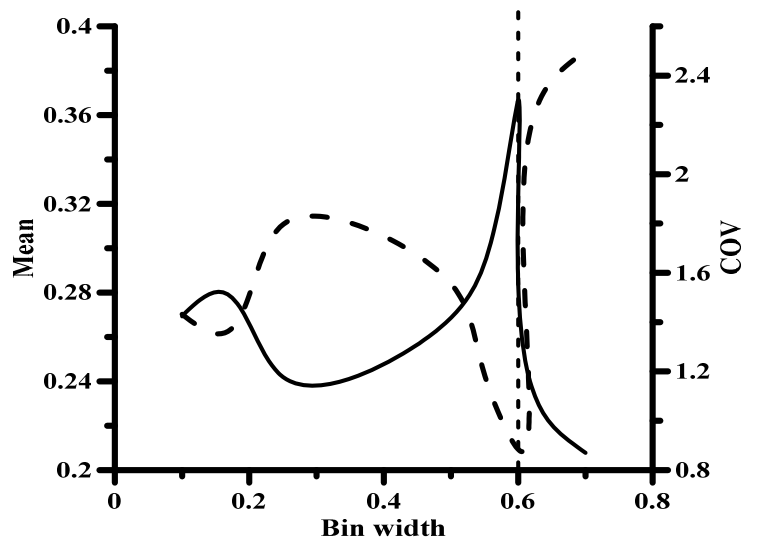

(b)

Figure 13 Best histogram bin width (interval) determination process. (a) Non-dimensional impact speed $\left(V_{\mathrm{i}} /\right.$ $\left.V_{\mathrm{s}}\right)$; (b) Trim angle $\left(\theta_{\mathrm{t}}\right)$

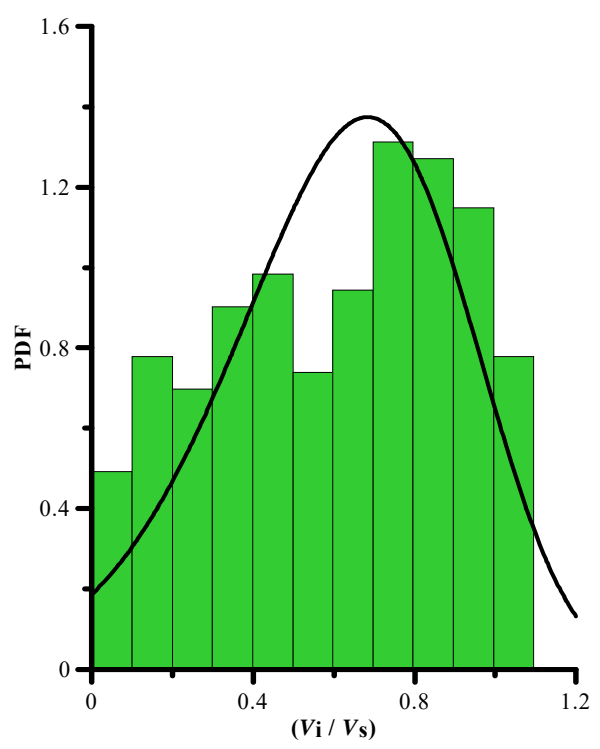

(a)

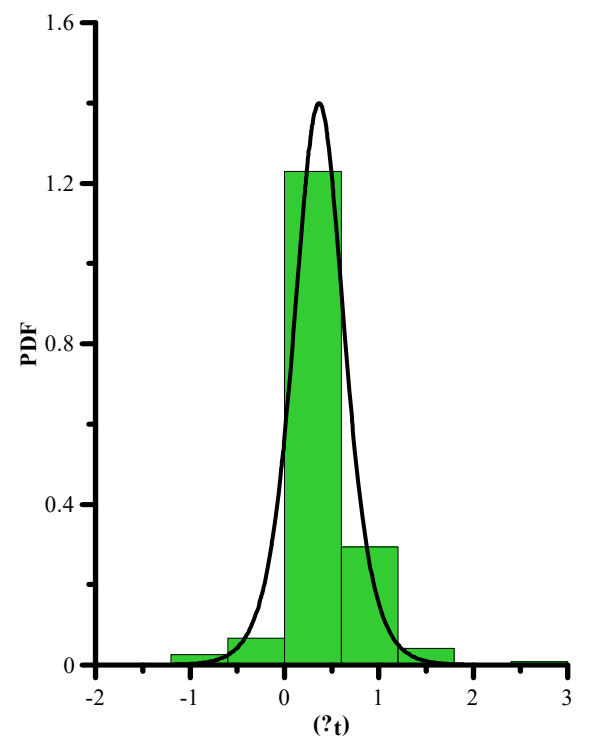

(b) 


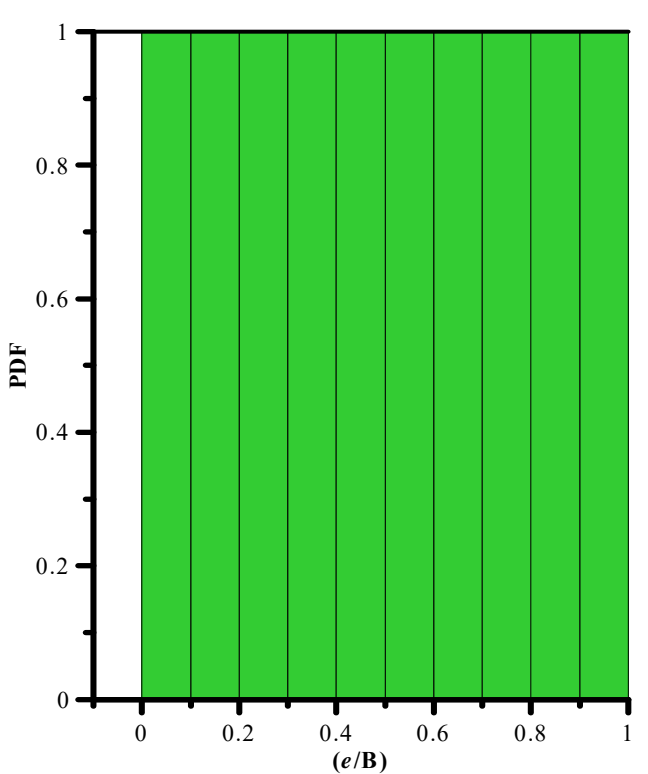

(c)

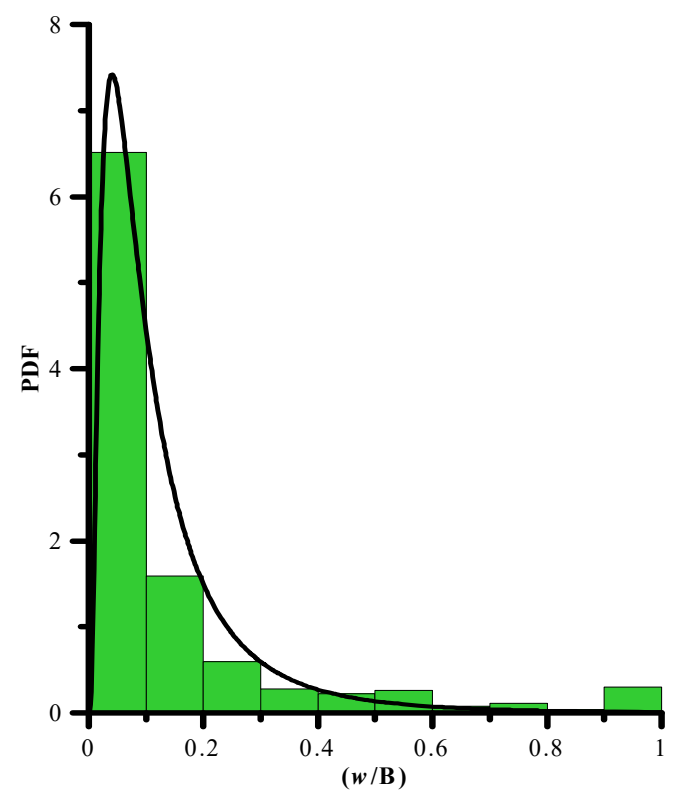

(e)

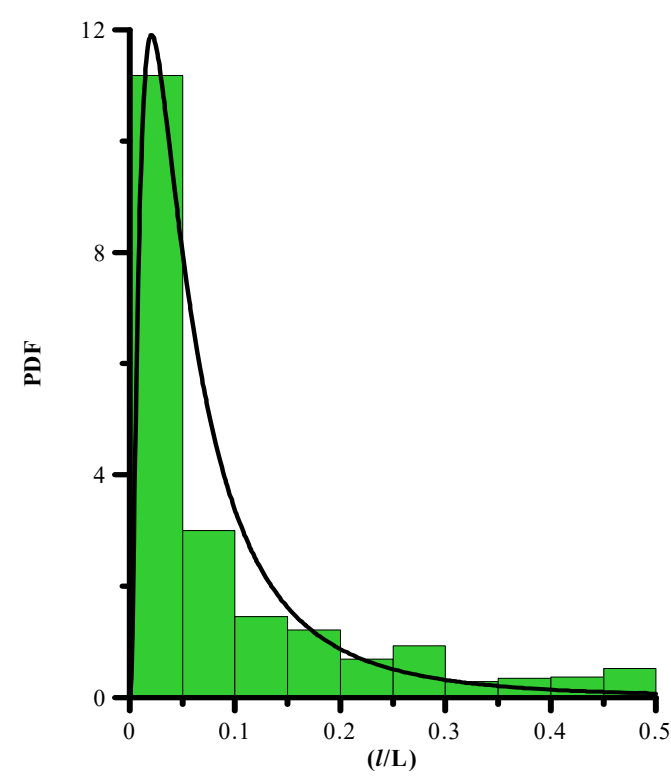

(d)

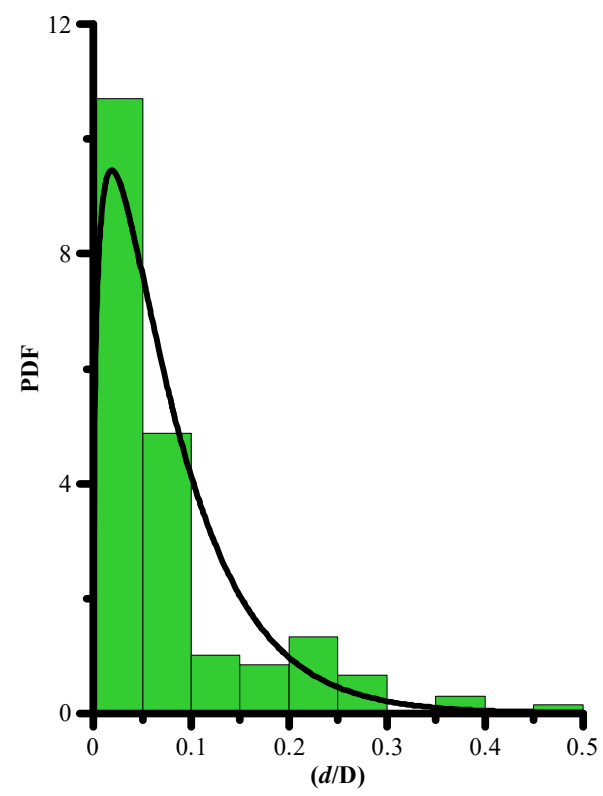

(f)

Figure 14 Selected pdfs for each grounding parameters. (a) Non-dimensional impact speed $\left(V_{\mathrm{i}} / V_{\mathrm{s}}\right)$; (b) Trim angle $\left(\theta_{t}\right)$; (c) Non-dimensional obstruction tip eccentricity $(e / \mathrm{B})$; (d) Non-dimensional obstruction length $(/ / L)$; (e) Non-dimensional obstruction width (w/B); (f) Non-dimensional obstruction elevation (d/D).

Table 3 Selected pdf characteristics for all types of ship category.

\begin{tabular}{ccccc}
\hline \multicolumn{5}{c}{ All types } \\
\hline$V_{\mathrm{i} /} / V_{\mathrm{s}}$ & $\theta_{\mathrm{t}}$ & $U_{\mathrm{L}}$ & $w / \mathrm{B}$ & $d / \mathrm{D}$ \\
\hline 3-P Weibull & Logistic & Lognormal & Lognormal & 2-P Gamma \\
\hline
\end{tabular}




\begin{tabular}{|c|c|c|c|c|c|c|c|c|c|}
\hline \multicolumn{2}{|c|}{$\mathrm{w}(6.526,1.697,-0.967)$} & \multicolumn{2}{|c|}{$\mathrm{L}(0.3666,0.1786)$} & \multicolumn{2}{|c|}{$\ln \mathrm{N}(-2.896,0.9912)$} & \multicolumn{2}{|c|}{$\ln \mathrm{N}(-2.41,0.8893)$} & \multicolumn{2}{|c|}{$\Gamma(1.313,0.06)$} \\
\hline Max & 1 & Max & 2.60256 & Max & 0.5 & Max & 1 & Max & 0.5 \\
\hline Min & 0.01622 & Min & -1.16914 & Min & 0 & Min & 0 & Min & 0 \\
\hline Interval & 0.09955 & Interval & 0.6 & Interval & 0.05 & Interval & 0.1 & Interval & 0.05 \\
\hline
\end{tabular}

\subsection{Individual ship categories}

The above steps are then applied to the other ship categories in the database until configuring the selected pdfs for each grounding scenario parameter is attained. The characteristics of the selected pdfs for tankers, bulk carriers, cargo vessels, container vessels and passenger vessels are recorded in Tables 4-8, respectively.

Table 4 Selected pdf characteristics for tankers.

\begin{tabular}{|c|c|c|c|c|c|c|c|c|c|}
\hline \multicolumn{10}{|c|}{ Tankers } \\
\hline \multicolumn{2}{|c|}{$V_{\mathrm{i}} / V_{\mathrm{s}}$} & \multicolumn{2}{|c|}{$\theta_{\mathrm{t}}$} & \multicolumn{2}{|c|}{$I / \mathrm{L}$} & \multicolumn{2}{|c|}{$w / \mathbf{B}$} & \multicolumn{2}{|c|}{$d / \mathbf{D}$} \\
\hline \multicolumn{2}{|c|}{ 2-P Weibull } & \multicolumn{2}{|c|}{ Logistic } & \multicolumn{2}{|c|}{ 2-P Gamma } & \multicolumn{2}{|c|}{ Lognormal } & \multicolumn{2}{|c|}{ 2-P Gamma } \\
\hline \multicolumn{2}{|c|}{ W(1.938,0.5998) } & \multicolumn{2}{|c|}{$\mathrm{L}(0.3966,0.1647)$} & \multicolumn{2}{|c|}{$\Gamma(1.242,0.07337)$} & \multicolumn{2}{|c|}{$\ln \mathrm{N}(-2.289,0.9598)$} & \multicolumn{2}{|c|}{$\Gamma(2.995,0.03151)$} \\
\hline Max & 1 & Max & 1.07742 & Max & 0.5 & Max & 1 & Max & 0.5 \\
\hline Min & 0.09375 & Min & 0 & Min & 0 & Min & 0 & Min & 0 \\
\hline Interval & 0.3 & Interval & 0.33 & Interval & 0.05 & Interval & 0.1 & Interval & 0.05 \\
\hline
\end{tabular}

Table 5 Selected pdf characteristics for bulk carriers.

\begin{tabular}{|c|c|c|c|c|c|c|c|c|c|}
\hline \multicolumn{10}{|c|}{ Bulk Carriers } \\
\hline \multicolumn{2}{|c|}{$V_{\mathrm{i}} / V_{\mathrm{s}}$} & \multicolumn{2}{|c|}{$\theta_{\mathrm{t}}$} & \multicolumn{2}{|c|}{$l / \mathrm{L}$} & \multicolumn{2}{|c|}{$w / \mathbf{B}$} & \multicolumn{2}{|c|}{$d / \mathbf{D}$} \\
\hline \multicolumn{2}{|c|}{ 3-P Weibull } & \multicolumn{2}{|c|}{ Normal } & \multicolumn{2}{|c|}{ 2-P Gamma } & \multicolumn{2}{|c|}{ Lognormal } & \multicolumn{2}{|c|}{ 2-P Gamma } \\
\hline \multicolumn{2}{|c|}{$\mathrm{W}(7.504,1.811,-1.068)$} & \multicolumn{2}{|c|}{$\mathrm{N}(0.2533,0.2323)$} & \multicolumn{2}{|c|}{$\Gamma(1.242,0.07337)$} & \multicolumn{2}{|c|}{$\ln \mathrm{N}(-2.289,0.9598)$} & \multicolumn{2}{|c|}{$\Gamma(2.995,0.03151)$} \\
\hline Max & 1 & Max & 1.07742 & Max & 0.5 & Max & 1 & Max & 0.5 \\
\hline Min & 0.07333 & Min & 0 & Min & 0 & Min & 0 & Min & 0 \\
\hline Interval & 0.24 & Interval & 0.17 & Interval & 0.05 & Interval & 0.1 & Interval & 0.05 \\
\hline
\end{tabular}

Table 6 Selected pdf characteristics for cargo vessels.

\begin{tabular}{|c|c|c|c|c|}
\hline \multicolumn{5}{|c|}{ Cargo Vessels } \\
\hline$V_{\mathrm{i}} / V_{\mathrm{s}}$ & $\theta_{\mathrm{t}}$ & $l / \mathbf{L}$ & $w / \mathbf{B}$ & $d / \mathbf{D}$ \\
\hline 3-P Weibull & Logistic & 2-P Weibull & 2-P Gamma & Lognormal \\
\hline $\mathrm{w}(2511,563,-562.2)$ & $\mathrm{L}(0.3469,0.1867)$ & $\mathrm{W}(0.8836,0.8363)$ & $Г(1.568,0.06549)$ & $\ln \mathrm{N}(-2.548,0.7144)$ \\
\hline $\operatorname{Max}$ & 1.47730 & Max & Max & Max \\
\hline
\end{tabular}




\begin{tabular}{cccccccccc} 
Min & 0.02857 & Min & -1.16914 & Min & 0 & Min & 0 & Min & 0 \\
Interval & 0.25 & Interval & 0.3 & Interval & 0.05 & Interval & 0.1 & Interval & 0.05 \\
\hline
\end{tabular}

Table 7 Selected pdf characteristics for container vessels.

\begin{tabular}{|c|c|c|c|c|c|c|c|c|c|}
\hline \multicolumn{10}{|c|}{ Container Ships } \\
\hline \multicolumn{2}{|c|}{$V_{\mathrm{i}} / V_{\mathrm{s}}$} & \multicolumn{2}{|c|}{$\theta_{\mathrm{t}}$} & \multicolumn{2}{|c|}{$l / \mathrm{L}$} & \multicolumn{2}{|c|}{$w / \mathbf{B}$} & \multicolumn{2}{|c|}{$d / \mathbf{D}$} \\
\hline \multicolumn{2}{|c|}{ Normal } & \multicolumn{2}{|c|}{ 3-P Gamma } & \multicolumn{2}{|c|}{ 2-P Weibull } & \multicolumn{2}{|c|}{ 2-P Gamma } & \multicolumn{2}{|c|}{ Lognormal } \\
\hline \multicolumn{2}{|c|}{$\mathrm{N}(0.6414,0.2324)$} & \multicolumn{2}{|c|}{$\begin{array}{c}\Gamma(0.3845,0.3414,0.02 \\
625)\end{array}$} & \multicolumn{2}{|c|}{$\mathrm{W}(0.8836,0.8363)$} & \multicolumn{2}{|c|}{$\Gamma(1.568,0.06549)$} & \multicolumn{2}{|c|}{$\ln \mathrm{N}(-2.548,0.7144)$} \\
\hline $\operatorname{Max}$ & 1 & Max & 0.36728 & Max & 0.5 & Max & 1 & Max & 0.5 \\
\hline Min & 0.016216 & Min & -0.04867 & Min & 0 & Min & 0 & Min & 0 \\
\hline Interval & 0.175 & Interval & 0.05250 & Interval & 0.05 & Interval & 0.1 & Interval & 0.05 \\
\hline
\end{tabular}

Table 8 Selected pdf characteristics for passenger vessels

\begin{tabular}{|c|c|c|c|c|c|c|c|c|c|}
\hline \multicolumn{10}{|c|}{ Passenger Ships } \\
\hline \multicolumn{2}{|c|}{$V_{\mathrm{i}} / \boldsymbol{V}_{\mathrm{s}}$} & \multicolumn{2}{|c|}{$\theta_{\mathrm{t}}$} & \multicolumn{2}{|c|}{$l / \mathrm{L}$} & \multicolumn{2}{|c|}{$w / \mathbf{B}$} & \multicolumn{2}{|c|}{$d / D$} \\
\hline \multicolumn{2}{|c|}{ Normal } & \multicolumn{2}{|c|}{ 2-P Weibull } & \multicolumn{2}{|c|}{ logistic } & \multicolumn{2}{|c|}{ Normal } & \multicolumn{2}{|c|}{ Normal } \\
\hline \multicolumn{2}{|c|}{$\mathrm{N}(0.5489,0.2854)$} & \multicolumn{2}{|c|}{$\mathrm{W}(1.13,0.365)$} & \multicolumn{2}{|c|}{$\mathrm{L}(0.1412,0.07504)$} & \multicolumn{2}{|c|}{$\mathrm{N}(0.1747,0.1112)$} & \multicolumn{2}{|c|}{$\mathrm{N}(0.1333,0.08523)$} \\
\hline Max & 1 & $\max$ & 1.16036 & $\max$ & 0.5 & Max & 1 & $\max$ & 0.5 \\
\hline Min & 0.08823 & $\min$ & 0 & $\min$ & 0 & Min & 0 & $\min$ & 0 \\
\hline Interval & 0.1 & Interval & 0.19 & Interval & 0.05 & Interval & 0.1 & Interval & 0.05 \\
\hline
\end{tabular}

\section{Probabilistic Selection of Grounding Scenarios}

The probability density functions determined in Section 5 are employed in a sampling process to stochastically select a limited number of grounding scenarios. In this study, the Latin hypercube sampling method (LHS) is used by implementing the selected pdfs to generate random values for each scenario parameters, with respect to the data range and variability. A Latin square is a square grid containing sample positions, if (and only if) there is only one sample in each row and each column. A Latin hypercube is the generalisation of this concept to an arbitrary number of dimensions, whereby each sample is the only one in each axis-aligned hyperplane containing it. By employing LHS, a total of 50 grounding scenarios are generated for 'All type of ships categories' as indicated in Table 3. Figure 15 shows the histograms fitted with pdfs for each grounding parameter of the selected 50 scenarios. To verify the selected scenarios resulted from the sampling, the comparisons shown in figure 16 illustrate historical data versus the selected 50 scenarios histograms fitted with the selected PDF for each grounding parameter. 
Table 9 Fifty grounding scenarios selected for all type of ship categories as an illustrative example

\begin{tabular}{|c|c|c|c|c|c|c|}
\hline & $V_{\mathrm{i}} / V_{\mathrm{s}}$ & $\theta_{t}$ & $e / \mathbf{B}$ & $\mathrm{I} / \mathrm{L}$ & $w / \mathbf{B}$ & $d / D$ \\
\hline 1 & 0.4533 & 0.2560 & 0.17 & 0.0334 & 0.1206 & 0.013953 \\
\hline 2 & 0.9400 & 0.6498 & 0.83 & 0.1273 & 0.1151 & 0.098368 \\
\hline 3 & 0.5875 & 0.7061 & 0.19 & 0.3080 & 0.1840 & 0.142854 \\
\hline 4 & 0.3321 & 0.4024 & 0.47 & 0.2550 & 0.0329 & 0.214667 \\
\hline 5 & 0.7671 & 0.3451 & 0.39 & 0.1957 & 0.0493 & 0.176504 \\
\hline 6 & 0.7411 & 0.1889 & 0.71 & 0.0163 & 0.4784 & 0.085338 \\
\hline 7 & 0.6904 & 0.4617 & 0.41 & 0.0414 & 0.0208 & $7.30 \mathrm{E}-03$ \\
\hline 8 & 0.4863 & 0.1704 & 0.49 & 0.0458 & 0.0411 & 0.134517 \\
\hline 9 & 0.0457 & 0.2716 & 0.61 & 0.0280 & 0.0960 & 0.045137 \\
\hline 10 & 0.3980 & 0.3016 & 0.91 & 0.0316 & 0.1265 & $1.63 \mathrm{E}-01$ \\
\hline 11 & 0.6397 & $-6.8 \mathrm{E}-03$ & 0.97 & 0.0393 & 0.0578 & 0.09377 \\
\hline 12 & 0.7804 & 0.8286 & 0.11 & 0.1608 & 0.1396 & $9.59 \mathrm{E}-03$ \\
\hline 13 & 0.9013 & 0.3738 & 0.37 & 0.0586 & 0.1733 & 0.022435 \\
\hline 14 & 0.7283 & 0.5265 & 0.07 & 0.0506 & 0.2257 & 0.103271 \\
\hline 15 & 0.5171 & -0.1593 & 0.03 & 0.0793 & 0.0608 & 0.07774 \\
\hline 16 & 0.5019 & 0.0568 & 0.89 & 0.0715 & 0.0840 & 0.02889 \\
\hline 17 & 0.6778 & 0.2067 & 0.43 & 0.4086 & 0.1961 & 0.055653 \\
\hline 18 & 0.5462 & 0.2867 & 0.63 & 0.0933 & 0.0438 & 0.0182 \\
\hline 19 & 0.5740 & 0.4772 & 0.51 & 0.0180 & 0.0878 & $2.07 \mathrm{E}-03$ \\
\hline 20 & 0.8078 & 0.1076 & 0.69 & 0.0558 & 0.0113 & 0.031092 \\
\hline 21 & 0.7541 & 0.7400 & 0.59 & 0.1048 & 0.0466 & 0.016083 \\
\hline 22 & 0.6139 & 0.4169 & 0.67 & 0.0145 & 0.0357 & 0.061398 \\
\hline 23 & 0.7156 & 0.6032 & 0.05 & 0.0127 & 0.0768 & 0.024567 \\
\hline 24 & 0.3065 & 0.5442 & 0.85 & 0.0196 & 0.1099 & 0.058479 \\
\hline 25 & 0.8674 & 0.6256 & 0.87 & 0.1479 & 0.0918 & 0.033325 \\
\hline 26 & 0.6008 & -0.0954 & 0.25 & 0.0836 & 0.0169 & 0.064419 \\
\hline 27 & 0.8220 & 0.8925 & 0.93 & 0.0680 & 0.3337 & 0.011796 \\
\hline 28 & 0.8517 & 0.4931 & 0.31 & 0.0107 & 0.2673 & 0.081446 \\
\hline 29 & 0.1162 & 0.4465 & 0.75 & 0.2206 & 0.2098 & 0.052913 \\
\hline 30 & 0.3775 & 0.3163 & 0.65 & 0.1115 & 0.1636 & $3.17 \mathrm{E}-01$ \\
\hline 31 & 0.3556 & 0.1300 & 0.99 & 0.0052 & 0.0273 & 0.114189 \\
\hline 32 & 0.2469 & -0.2542 & 0.35 & 0.0435 & 0.2446 & 0.108525 \\
\hline 33 & 0.6651 & 0.5824 & 0.33 & 0.1189 & 0.0803 & 0.089437 \\
\hline 34 & 0.5318 & -0.4541 & 0.09 & 0.0298 & 0.0734 & 0.050251 \\
\hline 35 & 0.9867 & 0.5628 & 0.23 & 0.1764 & 0.0638 & 0.037908 \\
\hline 36 & 0.6269 & -0.0467 & 0.13 & 0.0882 & 0.0242 & 0.047661 \\
\hline 37 & 0.6525 & 0.1508 & 0.15 & 0.0353 & 0.3878 & 0.127072 \\
\hline 38 & 0.4701 & 0.9874 & 0.27 & 0.0647 & 0.0669 & 0.040265 \\
\hline 39 & 0.9621 & 0.5095 & 0.79 & 0.0246 & 0.2959 & $4.86 \mathrm{E}-03$ \\
\hline 40 & 0.2784 & 0.6764 & 0.95 & 0.0753 & 0.0521 & 0.152337 \\
\hline 41 & 0.7030 & 0.0834 & 0.55 & 0.0481 & 0.1549 & 0.120339 \\
\hline
\end{tabular}




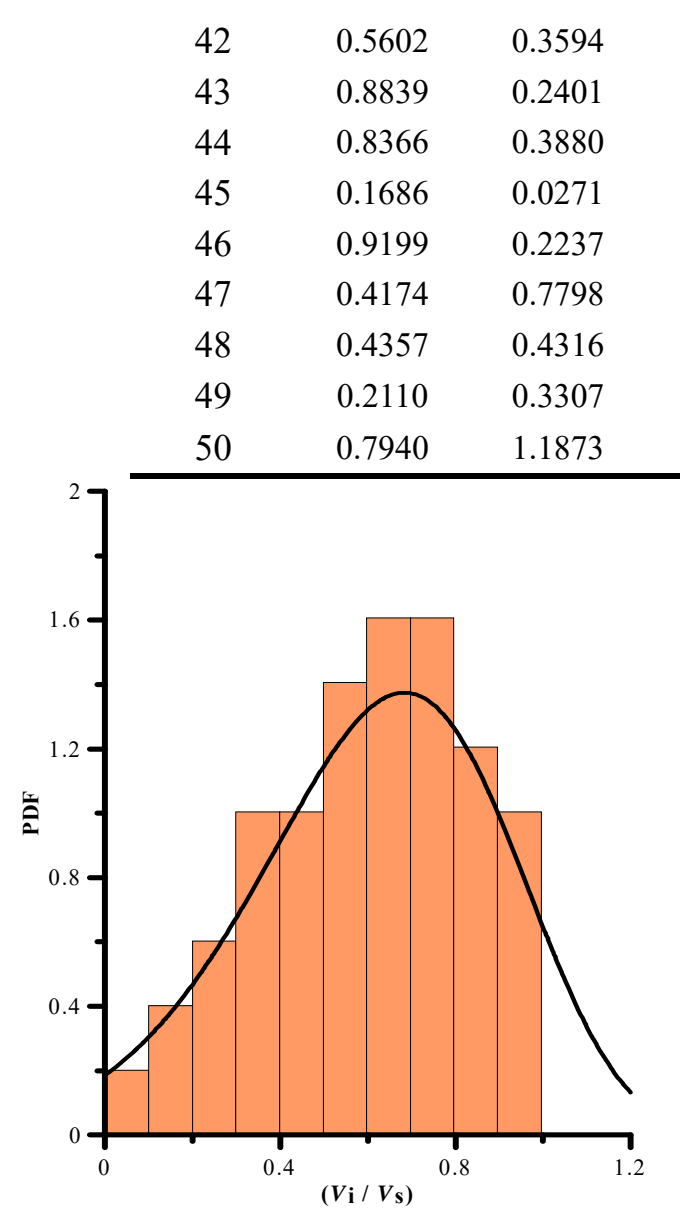

(a)

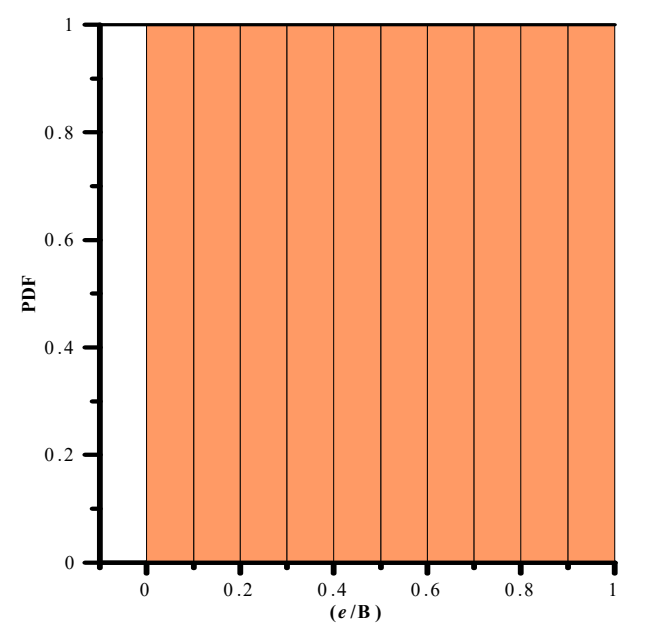

(c)

\begin{tabular}{llll}
0.77 & 0.0615 & 0.1004 & 0.247487 \\
0.21 & 0.0263 & 0.1051 & 0.070808 \\
0.45 & 0.1368 & 0.1328 & 0.035596 \\
0.01 & 0.0085 & 0.0549 & 0.020314 \\
0.53 & 0.0373 & 0.7109 & $1.93 \mathrm{E}-01$ \\
0.57 & 0.0531 & 0.0302 & 0.026717 \\
0.73 & 0.0230 & 0.0384 & 0.042673 \\
0.81 & 0.0988 & 0.1469 & 0.067552 \\
0.29 & 0.0213 & 0.0701 & 0.074199 \\
\hline
\end{tabular}

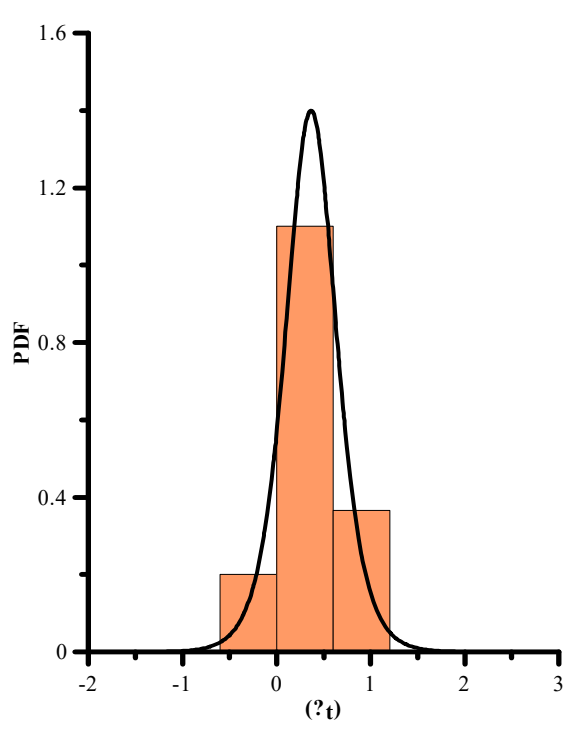

(b)

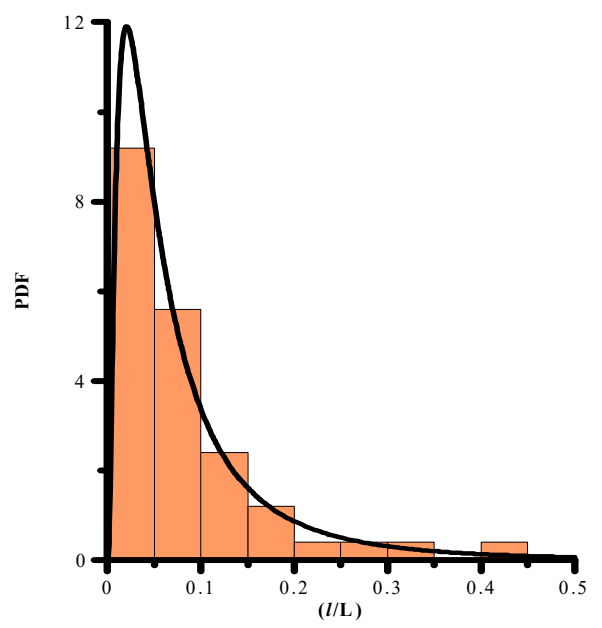

(d) 


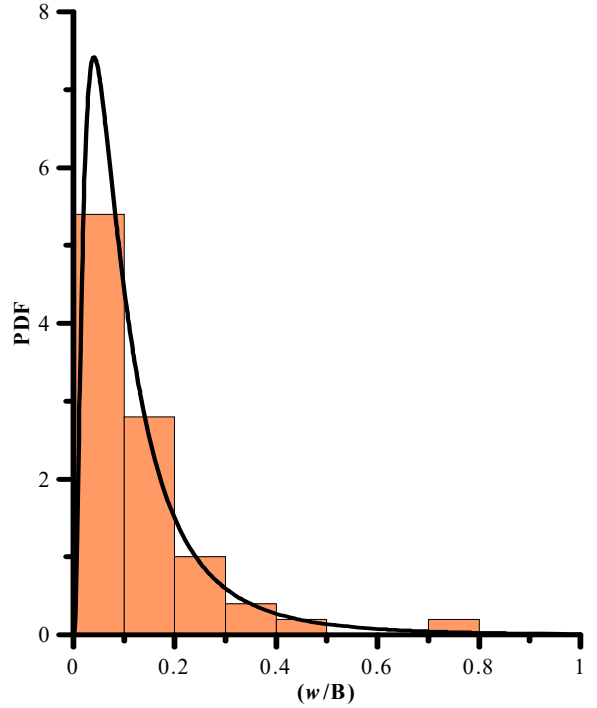

(e)

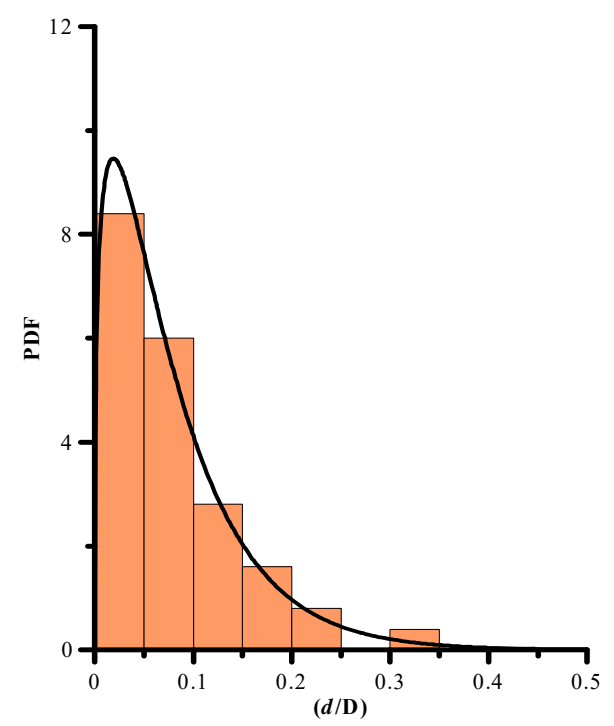

(f)

Figure 15 Histograms fitted with pdfs for each grounding parameter of the selected 50 scenarios. (a) Nondimensional impact speed $\left(V_{\mathrm{i}} / V_{\mathrm{s}}\right)$; (b) Trim angle $\left(\theta_{\mathrm{t}}\right)$; (c) Non-dimensional obstruction tip eccentricity $(e / \mathrm{B})$; (d) Non-dimensional obstruction length $(/ / \mathrm{L})$; (e) Non-dimensional obstruction width $(w / B)$; (f) Nondimensional obstruction elevation $(d / D)$.

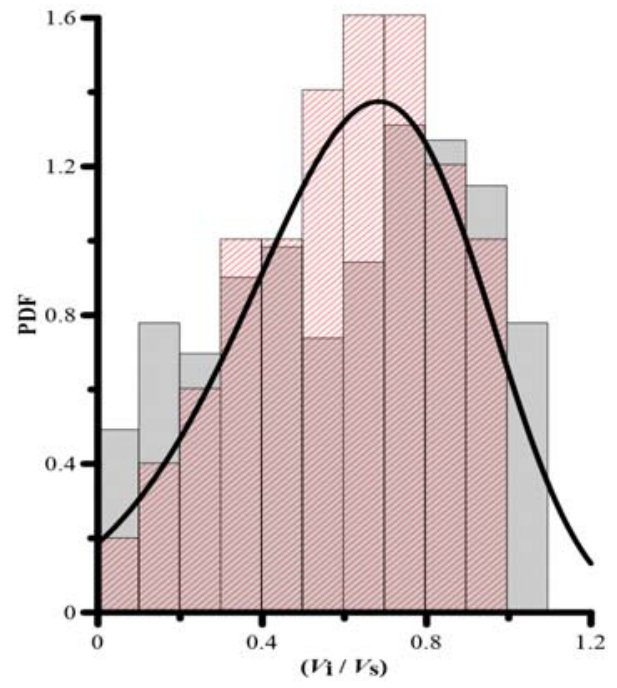

(a)

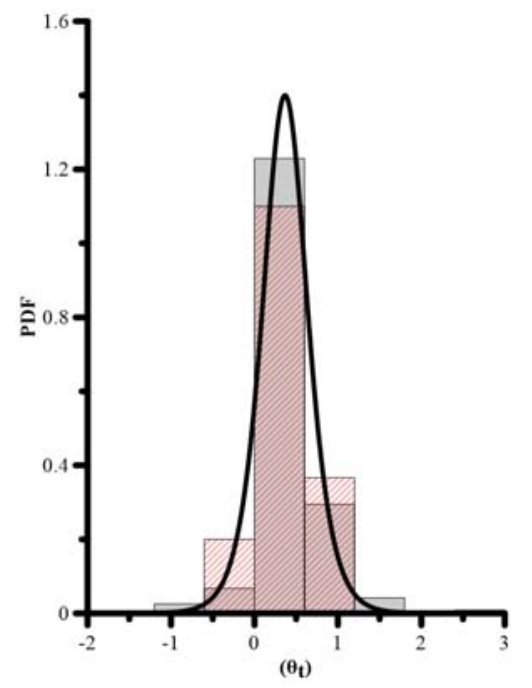

(b) 


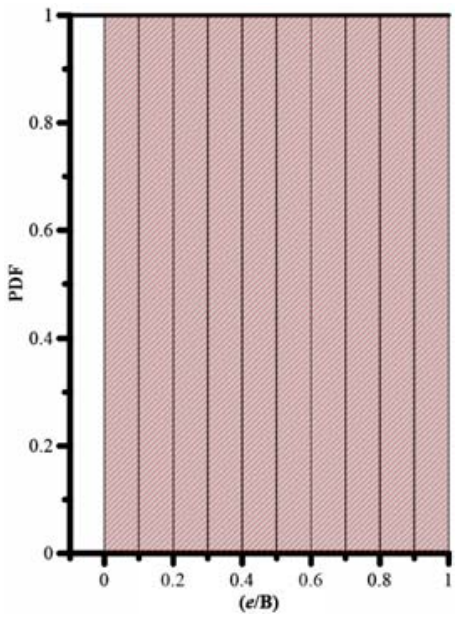

(c)

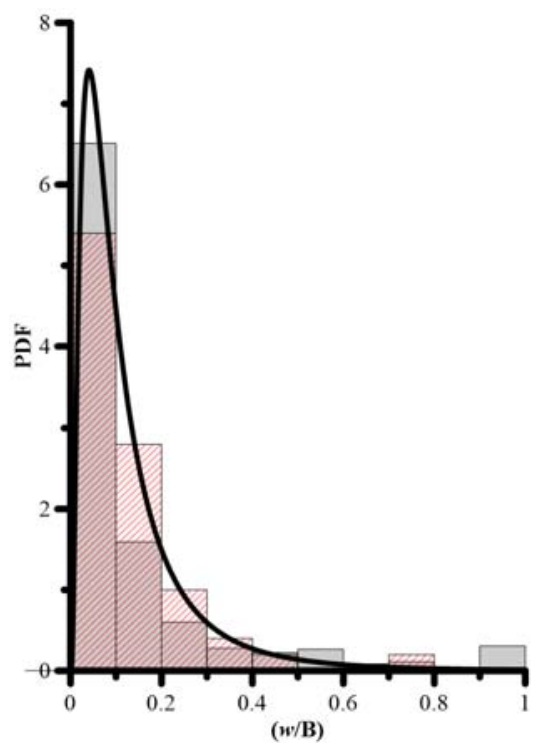

(e)

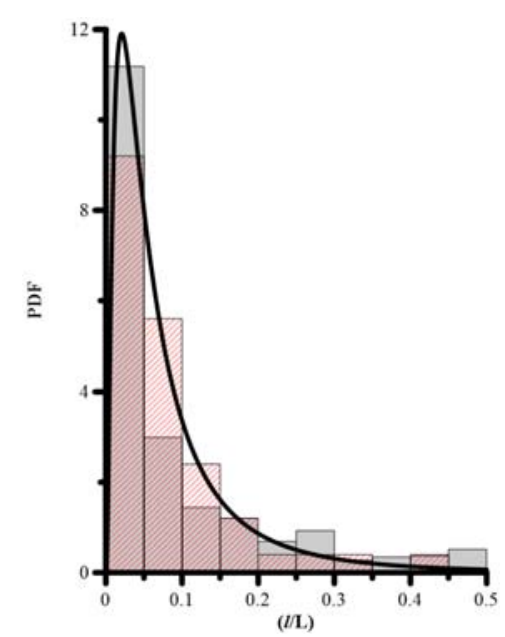

(d)

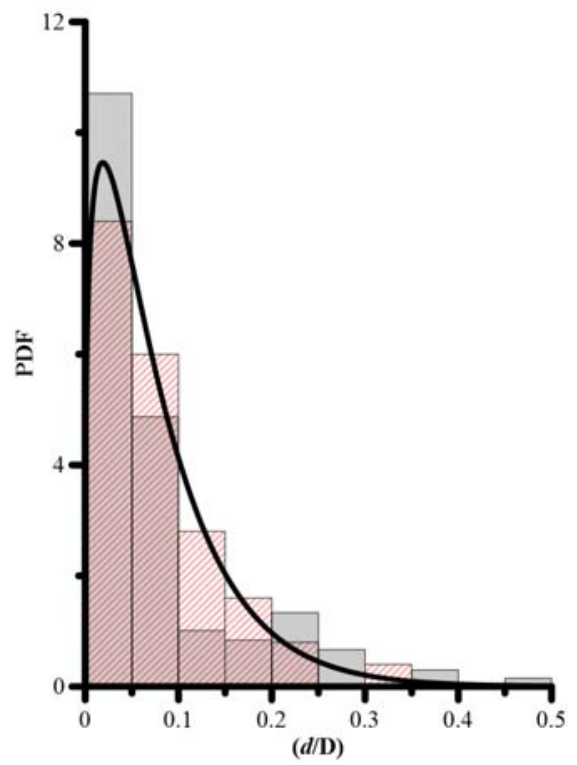

(f)

Figure 16 Comparison of the historical data versus the 50 scenarios histograms fitted with the selected PDF (a) Non-dimensional impact speed $\left(V_{\mathrm{i}} / V_{\mathrm{s}}\right)$; (b) Trim angle $\left(\theta_{\mathrm{t}}\right)$; (c) Non-dimensional obstruction tip eccentricity (e/B); (d) Non-dimensional obstruction length (l/L); (e) Non-dimensional obstruction width (w/B); (f) Nondimensional obstruction elevation $(d / D)$.

\section{Concluding Remarks and Further Work}

Grounding accidents are a threat at the maritime sector in terms of environmental and economic impacts, despite the cautionary measures devised recently as well as the developed navigational aids onboard. In overall, this paper aims at contributing to the decrease of the grounding consequences with an advanced technology to select a set of credible scenarios which are essential within the framework of quantitative grounding risk assessment and management. 
First, a database was gathered, consisting of information of grounding accidents that happened over the course of 46 years, from various sources. Then, this data was revised and filtered to delete doubles and check missing data that might have been glossed over in the accident reports. The accidents in the database were then analyzed to divide the vessel into categories based on their type and to understand the main parameters that can be used to define and adequately describe a grounding incident. A goodness of fit (GoF) test was carried next to choose the most suitable probability density function (pdf) that would best represent the distribution of the data of each of these parameters for every type of vessel. After that, the data was distributed as a histogram with optimum bin width for a better representation to the chosen pdf. The resulted histograms' particulars and the best-fit pdfs' shape parameters were then tabulated for an easier representation of the results. As a demonstrated example, the LHS method was used to randomize limited number of scenarios for all type of ships category, containing six non-dimensional parameters.

It was noticed that newly built vessels were more prone to experience grounding. This is may be come due to crew's inability and unfamiliarity to handle new technology equipment with the new ship. It also be noticed that the cargo vessels face more groundings compared to other types due to the nature of their shipping routes that mostly are short seas and trafficked coastal areas. On the other hand, old vessels (i.e., over 25 years) facing grounding with about $24.5 \%$ of the accidental database. This is because of several factors such as; degradations in the ship performance and the reliability of the mechanical, less advanced navigational equipment onboard as well as the improper bridge design. Concerning the ship speed at the moment of grounding, it was noted that the recorded speed lies between 80 and $100 \%$ of the ship's service speed due to a poor vessel's navigator awareness of the accident as well as no corrective actions prior the grounding event in some cases. The tabulated grounding parameters' pdf for diffirent type of vessels can be used to formulate a certain number of random scenarios to numerically simulate a reliable groundings with less uncertainty of the resulted damage. This in turn will be useful for grounding risk assessment.

Further works are now ongoing in terms of the analyses of frequency and consequences in association with selected grounding scenarios within the framework of quantitative grounding risk assessment.

\section{Acknowledgements}

The second author is president of the Korea Ship and Offshore Research Institute at Pusan National University which has been a Lloyd's Register Foundation Research Centre of Excellence.

\section{References}

AGCS, 2014. Global claims review 2014, Allianz Global Corporate \& Specialty, Munich, Germany.

AGCS, 2016. Allianz Global Corporate \& Specialty Safety and Shipping Review 2016, Munich, Germany.

AIBN, 2017. Published reports. Norwegian Accident Investigation Board, Trondheim, Norway.

Alsos, H.S., Amdahl, J., 2007. On the resistance of tanker bottom structures during stranding. Marine Structures 20 (4), 218-237.

ATSB, 2017. Marine safety investigations and reports. Australian Transport Safety Bureau, Canberra, Australia. 
BEAmer, 2017. Accidents full reports. French marine casualties investigation board, Paris, France.

BMA, 2017. Casualty and reporting. Bahamas Maritime Authority, Bahamas.

Brown, A., Amrozowicz, M., 1996. Tanker Environmental Risk-Putting the Pieces Together, Joint SNAME/SNAJ Conference on Designs and Methodologies for Collision and Grounding Protection of Ships, San Francisco, CA.

BSU, 2017. Investigation reports. The Federal Bureau of Maritime Casualty Investigation, Hamburg, Germany.

Bulian, G., Lindroth, D., Ruponen, P., Zaraphonitis, G., 2016. Probabilistic assessment of damaged ship survivability in case of grounding: development and testing of a direct non-zonal approach. Ocean Engineering 120, 331-338.

Bužančić Primorac, B., Parunov, J., 2016. Review of statistical data on ship accidents. Maritime Technology and Engineering, 809-814.

Cerup-Simonsen, B., Törnqvist, R., Lützen, M., 2009. A simplified grounding damage prediction method and its application in modern damage stability requirements. Marine Structures 22 (1), 62-83.

Chakravarty, I.M., Roy, J.D., Laha, R.G., 1967. Handbook of methods of applied statistics. In Handbook of methods of applied statistics. John Wiley \& Sons, New York.

Clarkson, P.L.C., 2017. Clarkson Shipping Intelligence Network, London, UK.

Deeb, H., Mehdi, R.A., Hahn, A., 2017. A review of damage assessment models in the maritime domain, Ships and Offshore Structures 12(S1), S31-S54.

DMIB, 2017. Casualty reports. Danish Maritime Accident Investigation Board, Carl Jacobsens Vej, Denmark.

Eleftheria, E., Apostolos, P., Markos, V., 2016. Statistical analysis of ship accidents and review of safety level. Safety science $85,282-292$.

EMSA, 2017. Accident investigation and marine casualties. European Maritime Safety Agency, LISBOA, Portugal.

Fowler, T.G., Sørgård, E., 2000. Modeling ship transportation risk. Risk Analysis 20 (2), 225-244.

Glykas, A., Das, P., 2001. Energy conservation during grounding with rigid slopes. Ocean Engineering 28 (4), 397-415.

GOALDS, 2009-2012. Goal-based damage stability. Project funded by the European Commission, FP7-DG Research.

HARDER, 1999-2003. Harmonization of rules and design rational. Project funded by the European Commission, DG XII-BRITE.

Haris, S., Amdahl, J., 2012. Crushing resistance of a cruciform and its application to ship collision and grounding. Ships and Offshore Structures 7 (2), 185-195.

HBMCI, 2017. Investigation reports. Hellenic Bureau for Marine Casualties Investigation, Piraeus, Grece.

Heinvee, M., Tabri, K., Kõrgesaar, M., 2013. A simplified approach to predict the bottom damage in tanker grounding, Collision and Grounding of Ships and Offshore Structures, p. 161.

Hong, L., Amdahl, J., 2008. Plastic mechanism analysis of the resistance of ship longitudinal girders in grounding and collision. Ships and Offshore Structures 3 (3), 159-171. 
Hong, L., Amdahl, J., 2012. Rapid assessment of ship grounding over large contact surfaces. Ships and Offshore Structures 7 (1), 5-19.

IMO, 1995. Interim guidelines for approval of alternative methods of design and construction of oil tankers under regulation 13F(5) of Annex I of MARPOL 73/78. Technical Report, 66 (73), 1-44.

IMO, 2002. IMO MSC/Circ. 1023 MEPC/Circ. 392-Guidelines for Formal Safety Assessment (FSA) for use in the IMO rule-making process. Maritime Safety Committee, International Maritime Organisation.

IMO, 2012. SLF55/INF.7-The GOAL based Damage Stability (GOALDS) - Derivation of updated probability distributions of collision and grounding damage characteristics for passenger ships Submitted by Denmark and the United Kingdom.

ITOPF, 2016. Oil tanker spill statistics 2015. International Tanker Owner's Pollution Federation.

JTSB, 2017. Marine accident and incident reports. Japan Transportation Safety Board, Tokyo, Japan.

Kaneko, F., 2012. Models for estimating grounding frequency by using ship trajectories and seabed geometry, Ships and Offshore Structures 7(1), 87-99.

Khan, I.A., Das, P.K., 2008. Reliability analysis of intact and damaged ships considering combined vertical and horizontal bending moments, Ships and Offshore Structures 3(4), 371-384.

Kuroiwa, T., 1996. Numerical simulation of actual collision and grounding accidents, Proceedings of Int. Conference on Design and Methodologies for Collision and Grounding Protection of Ships, San Francisco, California.

Liu, B., Villavicencio, R., Soares, C.G., 2015. Simplified analytical method to evaluate tanker side panels during minor collision incidents. International Journal of Impact Engineering 78, 20-33.

Lu, G., Calladine, C., 1990. On the cutting of a plate by a wedge. International Journal of Mechanical Sciences 32 (4), 293-313.

Lützen, M., Simonsen, B., 2003. Grounding damage to conventional vessels, World maritime technology conference, San Fransisco.

MAIB, 2017. Marine accident investigation branch reports. Marine accident investigation Branch, Southampton, UK.

MARDEP, 2017. Reports and statistics. Maarine Department-The Governement of the Hong Kong Special Administrative Region, Hong Kong.

MaritimeNZ, 2017. Investigation reports on maritime accidents and incidents. Maritime Newzealnd, Newzealnd.

MARS, 2017. MARS reports. Nautical Institue, London.

Mazaheri, A., 2009. Probabilistic modeling of ship grounding. Helsinki University of Technology, 48-56.

MCIB, 2017. Reports. The Marine Casualty Investigation Board, Dublin 2, Ireland.

MSA, 2017. Casualty investigation. Maritime Safety Administration of the People's Republic of China, Beijing, China.

Naar, H., Kujala, P., Simonsen, B.C., Ludolphy, H., 2002. Comparison of the crashworthiness of various bottom and side structures. Marine Structures 15 (4), 443-460. 
Nguyen, T.-H., Amdahl, J., Leira, B.J., Garrè, L., 2011a. Understanding ship-grounding events. Marine Structures 24 (4), 551-569.

Nguyen, T.-H., Garrè, L., Amdahl, J., Leira, B.J., 2011b. Monitoring of ship damage condition during stranding. Marine Structures 24 (3), 261-274.

NMD, 2011. Marine casualties 2000 - 2010. Norwegian Maritime Directorate, Haugesund, Norway.

NTSB, 2017. Marine accident reports. National Transportation Safety Board, Texas.

Paik, J.K., 1994. Cutting of a longitudinally stiffened plate by a wedge. Journal of ship research 38 (4), 340348.

Paik, J.K., 2007a. Practical techniques for finite element modeling to suimulate structural crashworthiness in ship collisions and grounding (Part I: Theory), Ships and Offshore Structures 2(1), 69-80.

Paik, J.K., 2007b. Practical techniques for finite element modeling to simulate structural crashorthiness in ship collisions and grounding (Part II: Verification), Ships and Offshore Structures 2(1), 81-85.

Paik, J.K., Kim, D.K., 2012. Advanced method for the development of an empirical model to predict timedependent corrosion wastage. Corrosion Science 63, 51-58.

Paik, J.K., Seo, J.K., 2007. A method for progressive structural crashworthiness analysis under collisions and grounding. Thin-Walled Structures 45 (1), 15-23.

Paik, J.K., Thayamballi, A.K., 2003. Ultimate limit state design of steel-plated structures. John Wiley \& Sons, New York.

Paik, J.K., Thayamballi, A.K., 2007. Ship-shaped offshore installations: design, building, and operation. Cambridge University Press, Cambridge, UK.

Papanikolaou, A., Eliopoulou, E., 2008. Impact of ship age on tanker accidents, 2nd international symposium on ship operations, management and economics, Athens, Greece.

Pedersen, P.T., Zhang, S., 2000a. Absorbed energy in ship collisions and grounding: Revising Minorsky's empirical method. Journal of ship research 44 (2), 140-154.

Pedersen, P.T., Zhang, S., 2000b. Effect of ship structure and size on grounding and collision damage distributions. Ocean Engineering 27 (11), 1161-1179.

Rawson, C., Crake, K., Brown, A., 1998. Assessing the environmental performance of tankers in accidental grounding and collision. SNAME Transactions 106, 41-58.

Rubinstein, R.Y., 1982. Simulation and the Monte Carlo method. John Wiley \& Sons, New York.

Samuelides, M., 2015. Recent advances and future trends in structural crashworthiness of ship structures subjected to impact loads, Ships and Offshore Structures 10(5), 488-497.

Samuelides, M., Ventikos, N., Gemelos, I., 2009. Survey on grounding incidents: Statistical analysis and risk assessment. Ships and Offshore Structures 4 (1), 55-68.

Senauth, F., 2013. The Sinking and the Rising of the Costa Concordia. AuthorHouse, IN.

SHK, 2017. Investigations. The Swedish Accident Investigation Authority, Stockholm, Sweden.

SIA, 2017. Investigation reports by year. Safety Investigation Authority, Helsinki, Finland.

Simonsen, B.C., 1997. Ship grounding on rock-II. Validation and application. Marine Structures 10 (7), 563584. 
Simonsen, B.C., Hansen, P.F., 2000. Theoretical and statistical analysis of ship grounding accidents. Journal of Offshore Mechanics and Arctic Engineering, Transactions of the ASME 122 (3), 200-207.

Sirkar, J., Ameer, P., Brown, A., Goss, P., Michel, K., Nicastro, F., Willis, W., 1997. A framework for assessing the environmental performance of tankers in accidental groundings and collisions. SNAME Transactions 105, 253-295.

Sormunen, O.-V.E., Castrén, A., Romanoff, J., Kujala, P., 2016. Estimating sea bottom shapes for grounding damage calculations. Marine Structures 45, 86-109.

Tikka, K., Chen, Y., 2001. Prediction of structural response in grounding application to structural design, SSC-417, Ship Structure Committee, Wasington DC.

TSB, 2017. Marine investigation reports. Transportation Safety Board of Canada, Gatineau, Canada.

Wang, G., Ohtsubo, H., Liu, D., 1997. A simple method for predicting the grounding strength of ships. Journal of ship research 41 (3), 241-247.

Wang, G., Spencer, J., Chen, Y., 2002. Assessment of a ship's performance in accidents. Marine Structures 15 (4), 313-333.

Ye, K.Q., 1998. Orthogonal column Latin hypercubes and their application in computer experiments. Journal of the American Statistical Association 93 (444), 1430-1439.

Youssef, S., Ince, S., Kim, Y., Paik, J., Chang, F., Kim, M., 2014a. Quantitative risk assessment for collisions involving double hull oil tankers. Transactions of the Royal Institution of Naval Architects Part A: International Journal of Maritime Engineering 156, 157-174.

Youssef, S., Kim, Y., Paik, J., Cheng, F., Kim, M., 2014b. Hazard identification and probabilistic scenario selection for ship-ship. Transactions of the Royal Institution of Naval Architects Part A: International Journal of Maritime Engineering 156, 61-80.

Youssef, S.A., Faisal, M., Seo, J.K., Kim, B.J., Ha, Y.C., Kim, D.K., Paik, J.K., Cheng, F., Kim, M.S., 2016. Assessing the risk of ship hull collapse due to collision. Ships and Offshore Structures 11 (4), 335-350.

Yu, Z., Hu, Z., Amdahl, J., Liu, Y., 2013. Investigation on structural performance predictions of doublebottom tankers during shoal grounding accidents. Marine Structures 33, 188-213.

Zeng, J., Hu, Z., Chen, G., 2016. A steady-state plate tearing model for ship grounding over a cone-shaped rock. Ships and Offshore Structures 11 (3), 245-257.

Zhang, A., Suzuki, K., 2006. Dynamic FE simulations of the effect of selected parameters on grounding test results of bottom structures. Ships and Offshore Structures 1 (2), 117-125.

Zhu, L., James, P., Zhang, S., 2002. Statistics and damage assessment of ship grounding. Marine Structures 15 (4), 515-530.

Zipfel, B., Lehmann, E., 2012. Evaluation of critical standing incidents, Ships and Offshore Structures 7(1), 101-118. 